\title{
THE POLITICAL ECONOMY OF DEBT BONDAGE ${ }^{1}$
}

\author{
Ulf von Lilienfeld-Toal ${ }^{2}$ and Dilip Mookherjee $^{3}$
}

June 262009

\begin{abstract}
Laws permitting bonded labor in a matching market for contracts subject to moral hazard are shown to have two contrasting effects: a partial equilibrium (PE) enhancement of commitment of agents' effort, and a general equilibrium (GE) impact via higher profits earned by principals. The GE effect operates when enough agents enter the market to fully utilize available capacity, creating a pecuniary externality which outweighs the PE effect on agent payoffs. Hence agents prefer minimal bonding limits consistent with full capacity utilization, while principals prefer higher limits. Efficiency may also decline with higher bonding limits if it is ex post distortionary. The model explains why low limits on bonding may be preferred politically or on normative grounds, when borrowers become more wealthy, and the range of collateral instruments widens.
\end{abstract}

\footnotetext{
${ }^{1}$ This paper is based on Part 2 of a paper earlier circulated with the title 'Bankruptcy Law, Bonded Labor and Inequality'. We thank seminar participants at Johns Hopkins University, MacArthur Inequality Network meetings, and the CSEF-IGIER Symposium on Economics and Institutions held at Anacapri in June 2006.

${ }^{2}$ Stockholm School of Economics

${ }^{3}$ Boston University
} 


\title{
THE POLITICAL ECONOMY OF DEBT BONDAGE
}

\author{
May 202009
}

\begin{abstract}
Laws permitting bonded labor in a matching market for contracts subject to moral hazard are shown to have two contrasting effects: a partial equilibrium (PE) enhancement of commitment of agents' effort, and a general equilibrium (GE) impact via higher profits earned by principals. The GE effect operates when enough agents enter the market to fully utilize available capacity, creating a pecuniary externality which outweighs the PE effect on agent payoffs. Hence agents prefer minimal bonding limits consistent with full capacity utilization, while principals prefer higher limits. Efficiency may also decline with higher bonding limits if it is ex post distortionary. The model explains why low limits on bonding may be preferred politically or on normative grounds, when borrowers become more wealthy, and the range of collateral instruments widens.
\end{abstract}




\section{Introduction}

A fundamental issue in contract law concerns restrictions on liability in the event of default. When borrowers or tenants default on their contractual payment obligations, lenders have various options available to extract resources and exert pressure for repayment. These options may include seizure of assets, appropriation of future earnings, and provision of indentured labor services. Contract law typically imposes restrictions on bonding arrangements: even ancient Greek and Roman societies imposed restrictions on debt bondage (Westermann (1955)). Imprisonment of debtors was widespread in the United States and United Kingdom until the 19th century; the death penalty was legal in England until 1820 for certain actions by a failing debtor (Coleman (1974), Lester (1995)). Despite legal bans, bonded labor is still widespread in the developing world, owing to weak enforcement. ${ }^{1}$ The Nepalese Kamaiya system is a well-known example (Joshi (2003), Edmonds and Sharma (2005)), rendered illegal by the Nepal government in $2000 .{ }^{4}$ In general, the process of economic development is associated with greater legal restrictions on ex post bonding, and modern international norms on labor standards do not allow any bonding.

A plausible reason for this is growing concern for human rights along the process of development. In this paper we focus instead on economic consequences of differing legal restrictions on bonding. Standard formulations of contract theory assume that agents are perfectly rational and can anticipate all relevant future consequences of contractual provisions. With such an approach it is difficult explaining why there are any legal limits on bonding at all. If borrowers voluntarily commit ex ante to an ex post bonding arrangement they should internalize all future consequences of these and trade them off against their ex ante advantages. ${ }^{5}$ Since bonding represents a form of precommitment, allowing a wider

\footnotetext{
${ }^{4}$ As the US Department of Labor report states: "Loans are a central feature for maintaining the Kamaiya system. Since Kamaiyas are generally not paid enough to meet their basic needs, many have no choice but to take loans from their master. Many also carry inherited debts, sometimes going back for three or four generations, in addition to their own. A Kamaiya burdened by debt must continue to work for the same landlord until the debt has been repaid. The Kamaiya remains bound to the landlord unless, at markets held each winter, the Kamaiya finds a new master to pay off his debt or the original master sells off the Kamaiya and his family to a new master".

${ }^{5}$ Of course, this pertains to committing one's own future labor services to pay off debts, rather than the
} 
range of bonding alternatives can widen access of agents to credit, tenancy or employment opportunities.

From this perspective, legal restrictions on bonding restrict market access, especially for poor borrowers. Indeed, it is frequently argued that default liability restrictions are inefficient and significantly impair the functioning of credit markets. ${ }^{6}$ Empirical evidence supporting these claims have been made both in cross-country as well as cross-U.S.-state analysis of correlations between lender rights and access of borrowers to finance (La Porta et al (1997, 1998), Gropp, Scholz and White (1997), Berkowitz and White (2004)). From this perspective, the best legal regimes are those with the strongest possible protection of lender rights and borrower rights.

Carrying this logic to an extreme, one is also led to question legal restrictions on bonded labor. From a consequentialist perspective, it appears to make little sense to not allow rational borrowers to commit themselves to providing indentured services to lenders should they lack the resources to repay their loans.

The purpose of this paper is to argue that economic rationales for bonded labor provisions do exist, even in a world of perfectly rational agents. The traditional argument against legal restrictions is based on partial equilibrium reasoning, which overlooks general equilibrium effects. Raising the legal limit on bonding (i.e., allowing more bonding) can raise profits earned by principals, thereby raising interest rates, which generates a negative pecuniary externality for all active agents. It turns out that the general equilibrium effect (when present) always outweighs the partial equilibrium benefits. Hence all active agents are worse off as a result of higher bonding limits, while principals are better off. Efficiency may also decline if bonding is ex post distortionary.

The details of our model are as follows. We study equilibrium contracts with moral hazard in a market with risk-neutral agents (tenants or borrowers) of heterogenous wealth on the one side, and a fixed set of homogenous risk-neutral principals (landlords or lenders)

labor of others (such as one's family members). Bonding the labor of other family members appears to be quite common in both historical and modern times; these clearly raise obvious questions of exploitation. The point we are raising concerns instead commitment of one's own future services.

${ }^{6}$ Basu (2003) and Genicot (2002) refer to this as a 'paradox of voluntary choice'. 
with given productive or lending capacities on the other. The agents seek to finance a project for which they lack a necessary asset or sufficient funds, and need to lease or borrow these. Project returns are ex ante uncertain and affected by costly effort they exert. After the project is completed and returns are realized, the agents have the opportunity to work on a spot labor market and earn a deterministic wage. If the law allows bonded labor, contracts allow agents to promise to provide part of their ex post labor earnings in payments on their project loans. These bonding arrangements may or not be distortionary, depending on whether the legal limits on bonding lie below or above ex post efficient spot labor supply levels. The limits on bonding define the limits of agent liability in the event that the project returns are insufficient to repay principals.

In this setting, we provide a detailed characterization of equilibrium allocations, using the solution concept of stability in the matching market for contracts between principals and agents (cf. Roth and Sotomayor (1990)). Comparative statics with respect to increased bonding limits include the partial equilibrium (PE) effect of agents' ability to credibly commit to bear greater liability in the event of project losses, and a general equilibrium (GE) effect on profits earned by principals. The PE effect is the basis of the conventional intuition of the beneficial effect of enlarging the set of feasible contracts for any agent. The novel aspect of our paper is the GE effect, which arises owing to competition in the market for contracts. When principals are on the short side of the market, they earn positive profits, the opportunities for which increase when the law allows more bonding. This effect counteracts the benign PE effects on agent payoffs, by generating a pecuniary externality.

Our main result is that whenever the GE effect operates (i.e., when enough agents are able to enter the market that all available capacity is fully utilized), it outweighs the PE effect, to render all agents worse off. The intuitive reason for this is clear in the case that bonding is non-distortionary: while the GE effect operates uniformly for all active agents, while the PE effect is stronger for poorer agents. And the poorest matched agent is worse off when additional bonding is possible, since she has (almost) no bargaining power with the principal she is matched with, given full utilization of capacity (i.e., the principals are on the short side of the market for contracts, which allows principals to threaten to replace any matched agent with an unmatched agent). Greater bonding opportunities therefore 
allow the principal matched with the poorest active agent greater opportunities to control the agent's incentives and limit the latter's rents. Hence the poorest matched agent cannot benefit, implying in turn (since the benefits are highest for poorer agents) that no matched agent can benefit. In the case when bonding is distortionary, the logic is somewhat more complicated, but continues to apply nonetheless.

Hence higher limits on bonding do not result in Pareto improvements, except in the case where GE effects are altogether absent (i.e., so few agents enter the market that there is unutilized capacity in the market). Political economy considerations (i.e., the interests of agents) can thus explain why there exist restrictions on bonding. Specifically, agents and principals have single-peaked preferences over the bonding limit, implying that bonding limits favored by agents will prevail under majority voting if agents outnumber principals. The equilibrium bonding limit will be the lowest consistent with allowing enough agents to enter the market to fully utilize all available capacity. This limit depends on the distribution of collaterizable wealth of agents. The model predicts higher levels of economic or financial development associated with rightward shifts of this distribution will lead to a reduction in the legal limit on bonding.

In contrast to payoff effects, efficiency and effort effects of higher bonding limits depend on whether bonding is ex post distortionary. If bonding is non-distortionary, allowing more bonding is shown to enhance effort and efficiency. But if it is distortionary, increasing bonding limits can result in a decrease in inefficiency, which may take the form of excessive supply of effort and ex post labor for a set of poor agents, or reduced efforts for some higher ranges of wealth. In the latter case, greater bonding may lower efficiency, as well as raise inequality (between the fortunes of agents and principals) and poverty (of agents). Hence the welfare effects of greater bonding can be adverse as well.

Section 2 introduces the model, and describes feasible allocations corresponding to a given legal limit on bonded labor. Section 3 provides a method for analyzing the equilibrium of the matching market for contracts between principals and agents, in terms of a set of interlinked optimal contracting problems. Using this, Section 4 provides a detailed characterization of equilibrium contracts. Comparative static effects of altering the bonding limit on welfare and implications for political economy of bonding laws are studied in Sections 5 
and 6 respectively. Section 7 discusses related literature. Finally, Section 8 concludes.

\section{Model}

The economy has a given population of $m$ principals and $n$ agents, in the context of a tenancy or credit market. Each agent can potentially operate a productive project of given, indivisible size. Each principal owns an asset such as a plot of land, equipment or finance that is needed for the project. Agents are prospective tenants or borrowers who do not own the asset themselves or cannot self-finance the project; principals are asset owners who are unable to provide the labor necessary to generate income from these assets. Principals may own more than one asset (or funds required to finance one project), and there are at least two distinct principals who compete with one another. ${ }^{2}$ The equilibrium is the same as the case where each principal owns a single asset, so we shall consider this setting for simplicity.

In order to generate income, the agent needs to spend an amount $I$ to purchase necessary inputs at the beginning of the period. Each agent starts with a given collateralizable wealth $w$. Principals have enough wealth to pay for the entire upfront investment. Consequently, a principal and agent pair that are matched with one another will need to agree how to share the investment costs, apart from how to share the incomes generated.

The returns to the project are stochastic. With probability $e$ the project is a success; the state of the world will be called good, and denoted by $s$. In that case the project return is $s$. With probability $1-e$ the project fails, the state of the world is bad, denoted by $f$, and the corresponding return is $f<s$. The success probability $e$ depends on the agent's effort, which is not observable by the principal or any third party. Without loss of generality, we can identify $e$ with the effort of the agent, which generates a disutility $D(e)$ for the agent, which is strictly convex, thrice differentiable, strictly increasing, with $D^{\prime \prime \prime}(e) \geq 0 .{ }^{3}$ We assume that $f<I<s$, so the project generates a net loss if the agents exerts no effort, and generates a net profit if sufficient effort is expended. Moreover, there exists a level of effort $e$ at which the project is viable, i.e., $e(s-f)+f>I+D(e)$.

With regard to pecuniary returns, principals and agents are risk-neutral. In case an agent or principal does not participate in the project they each earn zero payoff. Agents are 
distinguished from one another only by their wealth, while all principals are identical.

After the project has been completed, the agent can work $l$ hours on a spot labor market and earn an income of $R l$, where $R>0$ is a given wage rate. This opportunity arises irrespective of whether the agent participated in the project. The ex ante contract with the principal can specify an extent of labor that the agent is required to provide the principal ex post, depending on the outcome of the project and payments made by the agent. If $b$ units of labor are provided, the principal earns $R b{ }^{7}$ The agent then works a total of $b+l$, earns $R l$ and incurs a disutility of $g(b+l)$, where $g$ is a strictly increasing, convex and twice continuously differentiable function. There is an upper limit $\bar{l}$ on ex post labor supply, so $b+l \leq \bar{l}$. We assume that $g^{\prime}(\bar{l})=\infty$.

There is a legal limit $B$ on the extent of bonded labor that the agent can provide to the principal. Let $l^{*}$ denote the ex post efficient labor supply of the agent, i.e., where $g^{\prime}\left(l^{*}\right) \leq R$, with equality holding if $l^{*}=0$. If $l^{*}=0$, all bonded labor provided by the agent is ex post distortionary. If on the other hand $l^{*}>0$ and $0<B<l^{*}$, all bonded labor is nondistortionary, and is equivalent to an ex post transfer of assets or lumpsum redistribution from the agent to the principal. If $B>l^{*}$ then some bonding (up to $l^{*}$ ) is nondistortionary, and supplementary bonding (beyond $l^{*}$ ) is distortionary.

\subsection{Contracts, Legal Regimes and Sequence of Moves}

At Stage 1 there is matching of principals and agents. Then, the principal and the agent write a contract which specifies their respective contributions to the upfront investment $I$, financial transfers and bonded labor obligations, contingent on the outcome of the project. A contract specifies $I_{A}$, the contribution of the agent to the upfront investment, and for each outcome $i=s, f$ the financial transfer $\tilde{t}_{i}$ from the agent to the principal, and $b_{i}$ the bonded labor services provided ex post. A contract is feasible if $I_{A} \leq w, \tilde{t}_{i} \leq w-I_{A}+i$ and

\footnotetext{
${ }^{7}$ In our set up, the agent earns a wage rate of zero as a bonded laborer. In principle, the agent can earn any wage rate below $R$. This possibility will not change our results because any such contract can be replaced with a contract with a wage rate of zero and less bonded labor leaving the principal unaffected and making the agent (weakly) better off.
} 
$b_{i} \leq \min \{B, \bar{l}\} .^{8}$

At Stage 2, the agent selects effort $e$ and then the outcome $i$ is realized; the agent pays the mandated transfer $\tilde{t}_{i}$, and provides the mandated labor services $b_{i} \cdot{ }^{4}$

Finally at Stage 3 , the agent decides on supplementary labor supply $l^{s}$ to the spot labor market, subject to the constraint that the aggregate labor supplied does not exceed $\bar{l}$.

\subsection{Feasible Allocations}

We are interested in describing allocations that may result from feasible contracts in this setting. An allocation will specify a particular matching of agents with principals, and for any specific matched pair a state-contingent allocation of financial returns, ex post labor provided, and ex ante effort induced by these. Specifically, an allocation for a given matched pair is $\left(e,\left\{t_{i}, b_{i}, l_{i}^{s}\right\}_{i=s, f}\right)$ which satisfies the following conditions for feasibility: $0 \leq t_{i} \leq$ $w-I_{A}+i ; 0 \leq b_{i} \leq B ; l_{i}^{s} \in\left[0, \bar{l}-b_{i}\right]$ and $0 \leq e \leq 1$.

Such an allocation generates state contingent payoffs for the agent and principal respectively: $V_{i} \equiv w-I_{A}+i-t_{i}+R l_{i}^{s}-D(e)-g\left(b_{i}+l_{i}^{s}\right), \pi_{i} \equiv t_{i}-\left(I-I_{A}\right)+R b_{i}$. Let $v_{i}$ denote $w-I_{A}+i-t_{i}+R l_{i}^{s}-g\left(b_{i}+l_{i}^{s}\right)$, the agent's payoff net of the effort disutility. Let $l_{i}$ denote the aggregate ex post labor supplied $b_{i}+l_{i}^{s}$. We may then restate the state $i$ payoffs for the agent and the principal as $V_{i} \equiv v_{i}-D(e) ; \pi_{i} \equiv w-I+i-v_{i}+R l_{i}-g\left(l_{i}\right)$. The feasibility constraints above then reduce to

$$
v_{i} \geq R l_{i}^{s}-g\left(l_{i}\right)
$$

which corresponds to restrictions on financial transfers, and

$$
0 \leq b_{i} \leq B
$$

the restriction on bonded labor. Incentive compatibility includes an ex ante constraint

$$
v_{s}-v_{f}=D^{\prime}(e)
$$

\footnotetext{
${ }^{8}$ If the legal regime permits the contract to mandate a payment exceeding $w-I_{A}+i$, this is tantamount to allowing bonded labor, as the agent would be compelled to work on the spot labor market to be able to meet this obligation.
} 
and an ex post constraint

$$
l_{i}^{s}=\max \left\{l^{*}-b_{i}, 0\right\}
$$

equivalent to

$$
l_{i}=\max \left\{l^{*}, b_{i}\right\}
$$

on supply of project effort and of subsequent spot market labor respectively. Moreover, neither agent nor the principal should be worse off compared with autarky:

$$
\begin{gathered}
\Pi_{A} \equiv v_{f}+e D^{\prime}(e)-D(e) \geq w+S(R) \\
\Pi_{P} \equiv w+S(R)-I+e s+(1-e) f-v_{f}-e D^{\prime}(e)-e Q\left(l_{S}\right)-(1-e) Q\left(l_{f}\right) \geq 0 \quad\left(P C_{P}\right)
\end{gathered}
$$

Here $S(R) \equiv R l^{*}-g\left(l^{*}\right)$ denotes the maximum surplus resulting from the opportunity of the agent to supply labor to the spot market, and $Q(l) \equiv S(R)-[R l-g(l)]$ denotes the deadweight loss or reduction in surplus that results when the agent supplies a given level $l$ which may differ from the ex post efficient level $l^{*}$.

Definition. For a given agent, a contract is feasible if it satisfies (FT),(BL),(EAIC), (EPIC), $\left(P C_{A}\right)$ and $\left(P C_{P}\right)$. Let $\mathcal{F}(w ; B)$ denote the set of pair-wise feasible contracts for an agent with wealth $w$.

Feasibility incorporates physical, incentive and legal constraints, and ensures that both the agent and the principal who happens to provide the contract to the agent will earn at least their autarkic payoffs.

Definition. An agent with wealth $w$ is said to be viable with bonded labor limit $B$ if $\mathcal{F}(w ; B)$ is non-empty.

Clearly, non-viable agents cannot receive a contract from any principal: they must perforce be excluded from the market. This holds irrespective of the relative number of agents and principals, or the wealth distribution across agents. In specifying the pattern of matching, attention can therefore be restricted to the set of viable agents.

Definition. A feasible allocation is a matching of principals with viable agents, and for each matched agent a feasible contract. 
Attention can be further restricted to allocations in which for every matched pair, the contract offered to the agent cannot be Pareto dominated (among the pair) by another feasible contract. This motivates the following definition.

Definition. A feasible allocation is pair-wise Pareto-efficient (PE) if for every matched agent, there exists no other feasible contract which makes either the agent or the concerned principal better off ex ante without making the other worse off.

Pair-wise PE allocations can be found by maximizing linear welfare-weighted sum of utilities of the concerned principal and agent subject to the feasibility constraints $(\mathrm{FT}),(\mathrm{BL}),(\mathrm{EAIC}),(\mathrm{EPIC}),\left(P C_{A}\right)$ and $\left(P C_{P}\right)$. The following properties of Pair-wise PE allocations will turn to be useful later.

Proposition 1 (a) An agent with wealth $w$ who is viable with bonded labor limit $B$, is also viable with wealth $w^{\prime} \geq w$ at any bonded labor limit $B^{\prime} \geq B$.

(b) Attention can be restricted to pair-wise PE allocations in which $b_{i} \geq \min \left\{l^{*}, B\right\}$.

(c) In any pair-wise PE allocation, distortionary bonded labor $\left(b_{i}>l^{*}\right)$ will not be used in the success state $i=s$, and is distortionary in the failure state $\left(b_{f}>l^{*}\right)$ only if there is no further scope for increasing transfers: $t_{f}=w-I_{A}+f$.

Part (a) says that increasing the bonded labor limit enlarges the range of credible commitments, and may thus allow some previously non-viable agent to become viable. Part(b) states that bonded labor allowed by the law upto the limit $l^{*}$ of non-distortionary bonding will always be utilized, as an increase in non-distortionary bonding is akin to increasing the collateral that can be posted upfront by each agent. And part (c) says that distortionary bonded labor will only be used in the failure state, and only if maximal use of financial transfers in that state is being made. These results follow from the need to minimize the deadweight losses associated with provision of ex ante effort incentives. 


\section{Market Equilibrium}

Let the $n$ agents be ordered so that $w_{1} \geq w_{2} \geq w_{3} \ldots \geq w_{n}$. Let $n(B)$ be the largest integer $k$ between 1 and $n$ such that the agent with wealth $w_{k}$ is viable at bonded labor limit $B$. Then the market will realize matches between the $m$ principals and $n(B)$ agents, and assign a contract to each matched pair. We shall use the following standard definition of a stable allocation of a matching market:

Definition. An allocation is said to be stable if there does not exist any principal agent pair who can deviate to a pair-wise feasible allocation which makes at least one of them better off, and neither worse off. 9

Our characterization of stable allocations will make use of the following definitions of polar types of contracts that correspond to allocating all bargaining power to either principals or agents. 10

Definition. A P-optimal contract for an agent with wealth $w$ is a contract which maximizes the principal's payoff $\Pi_{P}$ over the feasible set $\mathcal{F}(w ; B)$. Let the corresponding level of profit be denoted $\Pi_{P}(w, B)$.

An A-optimal contract for agent with wealth $w$ relative to profit target $\bar{\Pi}$ for the principal is a contract which maximizes the agent's payoff $\Pi_{A}$ over the feasible set $\mathcal{F}(w ; B)$, subject to the additional constraint that the concerned principal earns a payoff of at least $\bar{\Pi}$.

Proposition 2 In any stable allocation:

(i) If $n(B)<m$, all principals attain zero profit, and every agent with $k \leq n(B)$ obtains an A-optimal contract relative to $\bar{\Pi}=0$. Agents with $k>n(B)$ are not matched.

(ii) If $n(B) \geq m$, all principals attain the same profit $\Pi^{*}$ which lies in the interval $\left[\Pi_{P}\left(w_{m+1}, B\right), \Pi_{P}\left(w_{m}, B\right)\right]$. All agents with $k \leq m$ obtain an A-optimal contract relative to $\Pi^{*}$. Agents with $k>m$ are not matched.

\footnotetext{
${ }^{9}$ In the previous version of this paper we showed the same characterization obtains if we require both deviators to be better off.

${ }^{10} \mathrm{~A}$ similar characterization is obtained under more general conditions by Dam and Perez-Castrillo (2006).
} 
Proof. In any stable allocation all principals must earn the same profit. Otherwise some principals will earn less than others, and the former can undercut the contracts offered by the latter to the agents they match with (i.e., offer a contract in which both $v_{s}$ and $v_{f}$ are increased by some common $\epsilon>0$, while all other details of the contract are unaffected).

If there are fewer viable agents than principals, then some principals will not be matched, and there will be principals that earn zero profit. Hence all principals must earn zero profit. Every agent with $k \leq n(B)$ must obtain an A-optimal contract relative to zero profits, otherwise there exists a contract which gives the agent a higher expected utility and breaks even for the principal. Agents with $k>n(B)$ cannot be matched since they are not viable.

If there are at least as many viable agents as principals, then the number of agents that will be matched will equal $m$, the number of principals. The $m$ wealthiest agents must be matched, otherwise an agent $k$ with wealth higher than the wealth of a matched agent $k^{\prime}$ will not be matched. The former can then offer the principal matched with agent $k^{\prime}$ the same contract, which generates the principal a higher profit owing to the higher wealth of agent $k$. Hence all agents with $k>m$ will not be matched. Moreover, all agents with $k \leq m$ will receive an A-optimal contract relative to $\Pi^{*}$. Finally $\Pi^{*} \leq \Pi_{P}\left(w_{m}, B\right)$ since the latter is the highest possible profit that can be attained by a principal contracting with the agent with wealth $w_{m}$. In addition, $\Pi^{*} \geq \Pi_{P}\left(w_{m+1}, B\right)$ otherwise any principal would do better offering a P-optimal contract with the agent $m+1$.

Hence competitive allocations can be described as follows: if principals are on the long side of the market, they make zero profits. If they are on the short side they make positive profits. The equilibrium profit equals the P-optimal profit with the marginal matched agent. All wealthier agents appropriate the entire surplus accruing from their wealth exceeding that of the marginal matched agent.

Note that the equilibrium profit is indeterminate if the principals are on the short side and the marginal matched agent has strictly higher wealth than the next wealthier agent who is excluded. This indeterminacy disappears if they have the same wealth $\left(w_{m}=w_{m+1}\right)$. When instead $w_{m}>w_{m+1}$, there is some surplus to be split between the marginal agent and the principal this agent is matched with. The principal's outside option is to contract with the agent with wealth $w_{m+1}$, while the outside option of the agent with wealth $w_{m}$ is autarky. 
We shall adopt the convention from now on that all the surplus will go to the principal in this case, i.e., the equilibrium profit rate $\Pi^{*}$ equals $\Pi_{P}\left(w_{m}, B\right)$. All qualitative results of this paper will remain unaltered if we replace this by an assumption of an exogenously fixed split of the surplus, as in a Nash bargaining solution. Moreover, the indeterminacy disappears as the economy becomes large and the distribution over wealth converges to a continuous distribution over the real line (though we eschew an explicit formulation of a large economy to keep the exposition simple and avoid purely technical complications).

With this convention, all the bargaining power is allocated to the principal in the match with the marginal agent. For an intramarginal agent on the other hand it is allocated entirely to the agent in question.

It is easy to check that we would obtain the same results from a Walrasian equilibrium of the contract market, where agents and principals take the 'going profit rate' as given and form utility or profit-maximizing demands and supplies of contracts respectively, and the profit rate is chosen so that the market for contracts clears.

\section{Characterization of Stable Allocations}

In this section we provide detailed properties of stable allocations, and the way they are affected by a change in the bonded labor limit. Before proceeding to the details, it will be helpful to gain some intuition for the contrasting effects associated with a change in the limit.

The first is the partial equilibrium (PE) or precommitment effect of allowing an enlargement of the set of feasible allocations, by relaxing the constraint (BL). For a given equilibrium profit level $\Pi^{*}$, every matched agent who obtains an A-optimal contract relative to $\Pi^{*}$ can now attain a higher level of expected utility. Moreover, the set of viable agents expands, by virtue of Proposition 1. So if viable agents are on the short side of the market, some agents who may have been previously excluded from the market because they were not viable, may now gain access because of the relaxation of constraint (BL) which may now allow a feasible contract to exist. The relaxation of (BL) relaxes the limited liability constraint, allowing the agent to now commit to accepting a lower level of utility 
in the failure state. The consequences of a greater bonded labor obligation in the event of project failure motivates the agent to exercise greater ex ante effort. Principals contracting with this agent now reduce their losses associated with project failure in two ways: first, by limiting their loss in the event of failure owing to their ability to compel the agent to work for them; second, by reducing the likelihood of project failure.

The second effect is the general equilibrium (GE) or profit effect. If principals are on the short side of the market and earn positive profit $\Pi^{*}$, an increase in the bonded labor limit $B$ may cause this profit to increase. An increase in $B$ enlarges the set of feasible contracts with the marginal agent $m$. For the very same reasons as above, the principal contracting with the marginal agent is able to earn a higher profit, thus raising the equilibrium profit rate. This lowers the utility of all intra-marginal agents. The net effect on the latter then depends on the relative intensity of the PE and GE effects.

The effects on access and profits are unambiguous in contrast, and do not require a detailed analysis of the nature of the PE and GE effects:

Proposition 3 An increase in the bonded labor limit $B$ to $B^{\prime}>B$ is associated with a (weak) increase in the number of matched agents, and in the equilibrium profit.

The first part follows from the expansion in the set of viable agents as $B$ increases, since the number of agents matched equals $\min \{m, n(B)\}$ and $n(B)$ is nondecreasing by virtue of Proposition 1. The second part follows from the fact that the equilibrium profit equals the P-optimal profit for the marginal agent: the latter must be nondecreasing in $B$ as an increase in $B$ enlarges the set of feasible contracts in the optimization exercise describing the P-optimal contract.

Hence principals always benefit (weakly) from relaxing limits on bonded labor. If access expands, agents that gain access will also be (weakly) better off. These follow from the $\mathrm{PE}$ effects alone. If agents are on the short side of the market both with $B$ and $B^{\prime}$, there is no GE effect, as equilibrium profits are zero both with $B$ and $B^{\prime}$, so all intra-marginal agents must continue to attain the same utility. In that case an increase in $B$ is (weakly) Pareto-improving. 


\subsection{Detailed Characterization: Nondistortionary Bonding}

Now consider the case where the bonding limit is high enough to allow at least $m$ agents to be viable, so all capacity will be fully utilized, and principals can earn positive profits. To address the question of how a change in $B$ affects agents payoffs, default rates or social surplus, we need to understand how the trade-off between conflicting PE and GE effects are resolved. This requires us to first understand detailed characteristics of the stable allocation at any given limit $B$ with this property; subsequently we can examine the comparative static effects of raising $B$. In this sub-section we focus on the simpler case where all bonding is nondistortionary $\left(B<l^{*}\right)$.

To focus on the nature of the GE effect, consider the P-optimal contract with the marginal agent with wealth $w_{m}$. This is a standard exercise in the analysis of profitmaximizing contracts with moral hazard and limited liability (see, e.g., Aghion and Bolton (1997), Holmstrom and Tirole (1997) or Mookherjee (1997)). The principal confronts two constraints: a participation constraint and an incentive constraint. Limits on the agent's liability constrains the extent to which incentives can be provided by imposing a strong punishment in the event of a failure. They need to be provided instead by paying the agent a reward in the event of success. Consequently, with strong limits on the agent's liability, providing the agent with high effort incentives requires paying a large enough 'carrot' for success, which allows the agent to earn an 'informational rent' above his autarkic outside option. This happens to be the case when the marginal agent is poor enough that his autarkic payoff is low.

The P-optimal contract in this case corresponds to the solution to a relaxed version of the principal's profit-maximizing problem, with the agent's participation constraint dropped. This relaxed version corresponds to choosing an effort level which maximizes $e(s-f)-$ $e D^{\prime}(e)$, since the marginal benefit of raising effort is the output difference $s-f$ between the success and failure states, while the marginal (expected) cost for the principal is the increase in the 'carrot' (measured by $D^{\prime}(e)$, the marginal disutility of the agent of higher effort) weighted by $e$, the probability of the success state where this carrot is paid. Let $\tilde{e}$ denote the effort that maximizes $e(s-f)-e D^{\prime}(e)$. 
The contract that solves the relaxed problem then provides the agent with the minimum consumption of 0 in the failure state, and a consumption of $D^{\prime}(\tilde{e})$ in the success state. This generates a profit to the principal of $w_{m}-I+R B-\tilde{e} D^{\prime}(\tilde{e})$, and an expected utility of $\tilde{e} D^{\prime}(\tilde{e})+S(R)-R B-D(\tilde{e})$ to the agent. Since the agent's autarkic payoff is $w_{m}+S(R)$, it follows that (PC) is satisfied at this solution if $\alpha(\tilde{e}) \equiv \tilde{e} D^{\prime}(\tilde{e})-D(\tilde{e})$ exceeds $w_{m}+R B$. In other words, the solution to the relaxed problem is indeed the solution if $w_{m}<\alpha(\tilde{e})-R B$.

A small increase in the bonded labor limit (to some $B^{\prime} \leq l^{*}$ which also satisfies $w_{m}<$ $\left.\alpha(\tilde{e})-R B^{\prime}\right)$ in this case allows the principal matched with the marginal agent to earn a higher profit, as it leaves the optimal effort unchanged at $\tilde{e}$. Recall from Proposition 1 that in the case of nondistortionary bonding, it is optimal for the agents to bond themselves to the limit. Hence a higher limit amounts to a lump-sum transfer from the marginal agent to the principal. Since the agent's participation constraint still does not bind (given $w_{m}<\alpha(\tilde{e})-$ $\left.R B^{\prime}\right)$, a higher transfer still allows this constraint to be be satisfied. Hence the principal can extract a higher profit at a constant rate $R$, while all other aspects of the P-optimal contract are unaffected. And the marginal agent is strictly worse-off, as its informational rent is reduced.

What about the impact on contracts of intra-marginal agents? Competition between principals now implies that the equilibrium profit rate must go up, as the principal contracting with the marginal agent is earning a higher profit, and all principals must earn the same profit. There are then two effects on the welfare of intra-marginal agents. The PE effect is favorable, as greater bonding allows the agents to commit credibly to higher efforts. On the other hand, the GE effect is unfavorable. As shown in the Appendix (Lemma 14), the A-optimal problem can be simplified to selection of effort to maximize the agent's payoff $f+e(s-f)-D(e)+w-I-\Pi$ subject to the constraint of generating enough 'pledgeable income' to meet the profit target for the corresponding principal:

$$
P(e)+w+R B-I \geq \Pi
$$

where $P(e)$ denotes $f+e(s-f)-e D^{\prime}(e)$.

In the A-optimal problem, the entire economic surplus at the margin accrues to the agent, so the agent's payoff varies in the same way as the first-best surplus $e(s-f)-D(e)$, 
which is maximized at the first-best effort $e_{F}$. The range of feasible efforts that the agent can credibly commit to, is described by the constraint (1). If the first-best effort meets this target, which would be the case for instance if the agent were sufficiently wealthy, the Aoptimal effort would be $e_{F}$. If the agent is not so wealthy, the effort will be selected to be the highest level consistent with (1). In either case note that a small rise in the bonding limit does not alter the credibility constraint (1), since the left-hand-side rises by exactly the same amount that the right-hand-side rises (as per the analysis of the P-optimal profit with the marginal agent). The former represents the PE effect and the latter the GE effect, and they exactly neutralize each other. Hence the A-optimal effort is left unaffected. Consequently the effect of a small rise in bonding on intra-marginal agents is the same as for the marginal agent: akin to a lumpsum transfer to their respective principals.

We summarize this discussion below.

Proposition 4 Suppose agent with wealth $w_{m}$ is viable at $B<l^{*}$, and $w_{m}<\alpha(\tilde{e})-R B$. Then the stable allocation is as follows (where $\tilde{e}$ denotes the level of e which maximizes $e(s-f)-e D^{\prime}(e)$, and $\alpha(e)$ denotes $\left.e D^{\prime}(e)-D(e):\right)$

The equilibrium profit rate is

$$
\Pi^{*}=w_{m}-I+f+\tilde{e}(s-f)-\tilde{e} D^{\prime}(\tilde{e})+R B
$$

which increases in $B$ at a constant rate $R$.

(i) The agent with wealth $w_{m}$ obtains a contract with bonded labor and effort $b_{f}\left(w_{m}\right)=$ $B, e\left(w_{m}\right)=\tilde{e}$ independent of $B$, and receives payoff $\Pi_{A}\left(w_{m}\right)=\alpha(\tilde{e})-R B$ which is strictly decreasing in $B$ at a constant rate $R$.

(ii) All agents with $w>w_{m}$ receive a contract with bonded labor $b_{f}(w)=B$ and effort (where $\hat{e}(w, \Pi \mid B)$ denotes the largest solution for $e$ in equation (1):

$$
e(w)=\min \left\{e_{F}, \hat{e}\left(w, \Pi^{*} \mid B\right)\right\}
$$

independent of $B$, and payoff $\Pi_{A}(w)=\alpha(e(w))-R B$ which also decreases locally in $B$ at constant rate $R$. 
Next we turn to the case where the marginal agent is not so poor as to earn an informational rent in the P-optimal contract. Then the PC binds in the P-optimal problem for the marginal agent, i.e., the agent receives exactly his autarkic payoff. Owing to the convexity of the P-optimal problem, this will continue to be the case when the bonding limit is raised. In contrast to the case covered by Proposition 4 above, a small rise in $B$ will leave the expected utility of the marginal agent unaffected. At the same time, it will raise the effort of this agent, as greater bonding enables an increase in effort. Specifically, in this case both the participation and incentive constraints bind simultaneously (unless the marginal agent is wealthy enough that the first-best effort is optimal). An increase in bonding leaves the autarkic payoff and hence the participation constraint unaffected, while lowering the cost of providing incentives. The rise in the extent of bonding allows the limit on the agent's liability to be lowered, i.e., the 'stick' for failure to be sharpened, so the same 'carrot' elicits higher incentives. Accordingly, it pays the principal to raise effort incentives, while continuing to preserve the participation constraint by compensating the agent exactly for the costs of additional effort. ${ }^{5}$ In turn this implies that the profit rate rises, but at a rate slower than $R$, owing to the need for the principal to compensate the marginal agent for higher effort.

How are intra-marginal agents affected? Again we have a contrast between the PE and GE effects which move in opposite directions. Since the profit rises at a slower rate than $R$, the right-hand-side of (1) rises more slowly than the rise in the left-hand-side. Hence the PE effect on the effort of wealth-constrained agents outweighs the GE effect, and their effort rises. The effect on their payoff is more difficult to sign, however. It turns out that in contrast to the effect on effort, the GE effect on agent payoffs outweighs the PE effect. The reason for this is that the payoff effect of rising $B$ for intra-marginal agents is less than it is for the marginal agent with wealth $w_{m}$. In turn this is because: (a) the effort of intra-marginal agents is closer to the first-best (since they are wealthier and can thus commit to greater effort), and (b) the increase in effort for these agents is smaller than it is for the marginal agent, owing to the concavity of the function $P(e)$. It follows from this that intra-marginal agents must be left worse off as $B$ rises, since the marginal agent's payoff is unchanged. 
Finally, in the case where the marginal agent is wealthy enough to achieve the first-best effort, the same is true for all intra-marginal agents, and a rise in $B$ leaves all contracts unaffected. We summarize this below.

Proposition 5 Suppose agent with wealth $w_{m}$ is viable at $B<l^{*}$, and $w_{m} \geq \alpha(\tilde{e})-R B$. Then the stable allocation is as follows.

(a) If $w_{m} \in\left[\alpha(\tilde{e})-R B, \alpha\left(e_{F}\right)-R B\right)$ : then

$$
\Pi^{*}=w_{m}-I+f+e_{m}(s-f)-e_{m} D^{\prime}\left(e_{m}\right)+R B
$$

where $e_{m}$ solves $\alpha\left(e_{m}\right)-R B=w_{m}$ and is strictly increasing in $B$.

(i) The agent with wealth $w_{m}$ obtains a contract with bonded labor $b_{f}\left(w_{m}\right)=B$, effort $e\left(w_{m}\right)=e_{m}$ which is less than $e_{F}$ and strictly increasing in $B$, and receives a payoff $\Pi_{A}\left(w_{m}\right)=w_{m}+S(R)$ which is independent of $B$.

(ii) All agents with $w>w_{m}$ receive a contract with bonded labor $b_{f}(w)=B$, effort $e(w)$ as given by (3) above, which is strictly increasing in $B$ if $e(w)<e_{F}$. The payoff of this agent is $\Pi_{A}(w)=\alpha(e(w))-R B$, which is strictly decreasing in $B$.

(b) If $w_{m} \geq \alpha\left(e_{F}\right)-R B$ : every matched agent attains a contract with first-best effort $e_{F}$, the bonded labor limit is not binding for any agent and a rise in $B$ leaves the equilibrium unaffected.

In summary, a rise in bonded labor limit within the nondistortionary range generally raises (or leaves unchanged) payoffs of principals and efforts of agents, and lowers (or leaves unchanged) payoffs of agents. Efforts rise only for those agents that are under-providing effort. Hence the net result is to raise efficiency (i.e., social surplus), while benefiting principals and hurting agents.

\subsection{Detailed Characterization: Distortionary Bonding}

Now we turn to the case where the bonding limit $B$ exceeds $l^{*}$. With distortionary bonding, the analysis becomes considerably more complicated, owing to a fundamental non-convexity 
in the P-optimal and A-optimal contracting problems. As shown in Proposition 1, distortionary bonding arises only in the failure state. The ex ante cost of these distortions equals $(1-e) Q\left(b_{f}\right)$, where $b_{f}>l^{*}$ if bonding is distortionary. ${ }^{11}$ Expressing the extent of bonding required to credibly commit to effort $e$ by an agent of wealth $w$ as $b_{f}(e, w)$, the expected distortionary cost of bonded labor entailed in implementing $e$ for an agent with wealth $w$ is $(1-e) Q\left(b_{f}(e, w)\right)$. This cost is non-convex in $e$ : a rise in $e$ necessitates a higher level of bonded labor, but at the same time it makes it less likely that the project will fail, i.e., the bonded labor obligation will have to be discharged. The marginal cost of effort $e$ equals

$$
D^{\prime}(e)-Q\left(b_{f}(e, w)\right)+(1-e) \frac{\partial Q\left(b_{f}(e, w)\right)}{\partial b_{f}} \frac{\left.\partial b_{f}(e, w)\right)}{\partial e}
$$

and it is difficult to say how this varies with $e$ or with $w$. Moreover, first-order conditions do not suffice to identify solutions to P-optimal or A-optimal contracting problems.

Despite this, we are able to obtain a characterization of stable allocations analogous to the case of nondistortionary bonding which enables us to evaluate the effects of changing the bonding limit.

As in the previous sub-section, we start with the analysis of the P-optimal contract in the case where the marginal agent is poor enough that the participation constraint does not bind. In this situation, an increase in bonding of the agent in the failure state is always advantageous for the principal, as it strengthens the agent's incentives without jeopardizing the agent's participation. Hence the marginal agent is bonded at the limit $b_{f}=B$, resulting in an expected profit for the principal which can be shown equal to ${ }^{6}$

$$
\Pi=P(e)-(1-e) Q(B)+g(B)+w+S(R)-I .
$$

The optimal effort is then $e^{*}(B)$ which maximizes $P(e)-(1-e) Q(B)$. Note that this is strictly increasing in $B$. Intuitively, one of the benefits of higher effort is that it reduces the chances of having to incur the bonded labor obligation $B$, which arises in the failure state. The higher the bonding limit, the more pressing this consideration becomes, and the agent is induced to select higher effort. Note the contrast with the case of nondistortionary bonding,

\footnotetext{
${ }^{11}$ In this case the agent oversupplies labor to the principal, and will therefore not supplement it with additional supply to the spot market. Hence aggregate labor supply equals $b_{f}$ when it exceeds $l^{*}$.
} 
where a local increase in the limit $B$ left all aspects of the contract with the marginal agent unaffected, including the induced effort.

In this case there will be a GE effect: profits will rise, as verified by applying the Envelope Theorem to (5). The higher extent of bonding as well as the higher effort ensures that the marginal agent is worse off.

Evaluating the effect on intra-marginal agents is more complicated, owing to the nonconvexity of the A-optimal problem. In particular it is difficult to identify whether (or which) agents will be bonded at the limit $B$, i.e., whether there is a PE effect associated with a rise in $B$. While an interval of wealth levels in a right neighborhood of $w_{m}$ can be shown to be bonded at the limit just like the marginal agent, once wealth rises sufficiently the distortionary costs of bonding may not be worthwhile for the agent to bond at the limit (since she can commit anyway to high levels of effort by posting enough wealth as collateral). The nonconvexity of the costs of bonding however makes it possible that agents of still higher wealths may again wish to bond at the limit. The pattern of bonding may be non-monotone in wealth, which makes it difficult to identify when the PE effect does or does not arise.

Nevertheless the effect on the payoffs of all these agents can be signed, using the following approach. Partition the set of matched agents into those that are bonding at the limit, and those that are not. For the latter group, there is no PE effect at the margin as $B$ is raised, so these agents must be hurt at the margin owing to the adverse GE effect. The former group are all using the same amount of bonded labor as the marginal agent, so it is possible to compute their efforts and payoffs, and assess directly how these change as $B$ rises. It turns out that the intra-marginal agents are also adversely affected, though the reasoning underlying this is quite involved; the details are available in the Appendix. Not surprisingly, for this set of agents as well, an increase in $B$ induces an increase in effort.

This discussion is summarized as follows.

Proposition 6 Suppose agent with $w_{m}$ is viable at $B>l^{*}$, and $w_{m}<\gamma(B)-S(R)$, where $e^{*}(B)$ denotes the solution to the equation $P^{\prime}\left(e^{*}\right)+Q(B)=0$, and $\gamma(B)$ denotes $\alpha\left(e^{*}(B)\right)-g(B)$, a function which is strictly decreasing in $B$. Then stable allocations have 
the following properties:

The equilibrium profit is

$$
\Pi^{*}=w_{m}-I+P\left(e^{*}(B)\right)+e^{*}(B) Q(B)+R B
$$

which is strictly increasing in B.

(i) The agent with wealth $w_{m}$ gets a contract with bonded labor $b_{f}\left(w_{m}\right)=B$, effort $e^{*}(B)$ both strictly increasing in $B$, and payoff $\Pi_{A}=\gamma(B)$ strictly decreasing in $B$.

(ii) There exists $\epsilon>0$ such that for all $w \in\left[w_{m}, w_{m}+\epsilon\right)$, agents with wealth $w$ receive a contract with bonded labor $b_{f}(w)=B$, effort $e(w)=\hat{e}\left(w, \Pi^{*} \mid B\right)$ both strictly increasing in $B($ where $\hat{e}(w, \Pi \mid B)$ denotes the largest solution for $e$ in the equation $f+e(s-f)-$ $\left.e D^{\prime}(e)=\Pi+I-w-R B-e Q(B)\right)$, and payoff $\Pi_{A}(w)=\alpha(e(w))-g(B)$ which is strictly decreasing in $B$.

(iii) Agents with $w>w_{m}+\epsilon$ receive a payoff $\Pi_{A}(w)$ which is strictly decreasing in $B$.

(iv) For $w$ sufficiently large, $b_{f}(w)=l^{*}, e(w)=e_{F}$ and payoff $\Pi_{A}(w)=f+e_{F}(s-f)-$ $D\left(e_{F}\right)+w-I-\Pi^{*}$.

It remains to consider the case where the marginal agent is not poor enough to earn informational rents. Here, too, the analysis is quite involved and the details are available in the Appendix. The structure of the argument used is similar to the previous Proposition, and the results concerning payoff effects are similar.

Proposition 7 Suppose agent with $w_{m}$ is viable at $B>l^{*}$, and $w_{m} \geq \gamma(B)-S(R)$. Define $B_{1}^{*}$ by the condition $w_{m}=\gamma\left(B_{1}^{*}\right)-S(R)$ (so we have $B \geq B_{1}^{*}$ in this case, whilst $B<B_{1}^{*}$ in the case considered in Proposition 6 above). There exists $B_{2}^{*} \geq B_{1}^{*}$ such that if $B \in\left[B_{1}^{*}, B_{2}^{*}\right)$, the stable allocation is as follows.

(i) There exists $\delta>0$ such that for all $w \in\left[w_{m}, w_{m}+\delta\right)$, an agent gets a contract with $b_{f}(w)=B$, effort $e(w)=\hat{e}\left(w, \Pi^{*} \mid B\right)$ both strictly increasing in $B$, while equilibrium profit $\Pi^{*}=w_{m}-I+R B+P\left(e\left(w_{m}\right)\right)+e\left(w_{m}\right) Q(B)$ is strictly increasing in B. For all agents with wealth $w \in\left(w_{m}, w_{m}+\delta\right)$, utility $\Pi_{A}$ is strictly decreasing in $B$ and utility of agents with $w_{m}$ is constant in $B$. 
(ii) All agents with $w>w_{m}+\delta$ get a payoff $\Pi_{A}(w)$ which is strictly decreasing in $B$.

(iii) For $w$ sufficiently large, $b_{f}(w)=l^{*}, e(w)=e_{F}$ and payoff $\Pi_{A}(w)=f+e_{F}(s-f)-$ $D\left(e_{F}\right)+w-I-\Pi^{*}$.

Finally, if $B>B_{2}^{*}$ then $b_{f}(w)<B$ for all matched agents, and local variations in $B$ have no effect on the allocation.

\section{$5 \quad$ Welfare Effects of Raising Bonding Limits}

While the case with distortionary bonding differs from the non-distortionary case in many respects, the effects on equilibrium payoffs therefore turn out to be similar: whenever there is some effect on the allocation, agents are worse off while principals are better off. Again, with respect to payoffs, the GE effects outweigh the PE effects. The payoff effects can be summarized simply as follows:

\section{Corollary 1.}

(i) Suppose the agent with wealth $w_{m}$ is not viable at bonding limit B. Then the equilibrium profit is zero, unaffected by local variations in $B$, while agent payoffs are locally nondecreasing in $B$.

(ii) Suppose the agent with wealth $w_{m}$ is viable at bonding limit $B$. If an increase in $B$ has any effect on the equilibrium allocation, it raises equilibrium profits, makes all principals (strictly) better off, and all agents (weakly) worse off, with some agents strictly worse off.

In case (i), capacity is underutilized and principals are on the long side of the market. Profits are zero, and increases in $B$ only have a favorable PE effect, allowing agents at or near the margin to become viable and thus enter the market. This is the basis of the

conventional intuition concerning a relaxation of limits on contract liability: by enlarging the set of feasible contracts, they enable a Pareto improvement. 
The picture changes if the principals are on the short side of the market, which requires the wealth of the marginal agent (i.e., with wealth $w_{m}$ ) to be high enough relative to the bonding limit so as to render this agent viable. In this case, an increase in bonding allows principals to attain a higher profit, by increasing instruments of control available to the principal contracting with the marginal agent. This generates a GE effect, which overwhelms the PE effect for all matched agents. Here the interests of principals and agents are opposed, while all agents are affected the same way. ${ }^{12}$

Of course, there is a case where the GE effect disappears, even when the marginal agent is viable: this is when the marginal agent is wealthy enough that the bonding limit does not bind even in the P-optimal contract. This can happen if the marginal agent can achieve the first-best effort by offering enough financial collateral, so labor bonding is unnecessary. Alternatively, it can happen if the distortionary costs of bonding at the limit $B$ are too high, that not even the marginal agent operates at the limit. Such cases are uninteresting as changes in the bonding limit have no effect at all on the equilibrium.

Figure 1 provides a graphical illustration of the payoff implications of changes in laws regulating bonding. Bonding limits are represented on the horizontal axis, while the vertical axis plots the common payoff of principals, and the payoff of agents with differing wealths. The agent with wealth $w_{i}$ becomes viable at bonding limit $B_{i}, i=1,2, .$. , and the agent with wealth $w_{m}$ becomes viable at limit $B^{*}$. The limit $B^{*}$ is the threshold for full capacity utilization. Below this threshold, agents with successively lower wealths can enter and experience a discrete upward jump in payoffs at the point of entry. Subsequent increases in $B$ allow their payoffs to increase smoothly as a result of the PE effect, while the GE effect is inoperative over this range. As soon as the bonding limit is raised above $B^{*}$, the GE effect

\footnotetext{
${ }^{12}$ This result relies on the assumption of a fixed number of principals, i.e., the absence of any effects of the profit rate on the number of active principals. Consider an extension of our model where principals incur heterogenous fixed costs, whence a rise of the profit rate on contracts will invite greater entry of principals. In this case poorer agents may prefer higher bonding limits, owing to the effect of bonding limits on their access to contracts. Nevertheless, our main qualitative result below will continue to hold: as the distribution of $w$ shifts to the right, the ideal policy of every agent will entail a lower bonding limit, while all principals will continue to prefer higher bonding limits. Hence the majority rule equilibrium policy will entail lower bonding limits following a rightward shift in the distribution of $w$.
} 


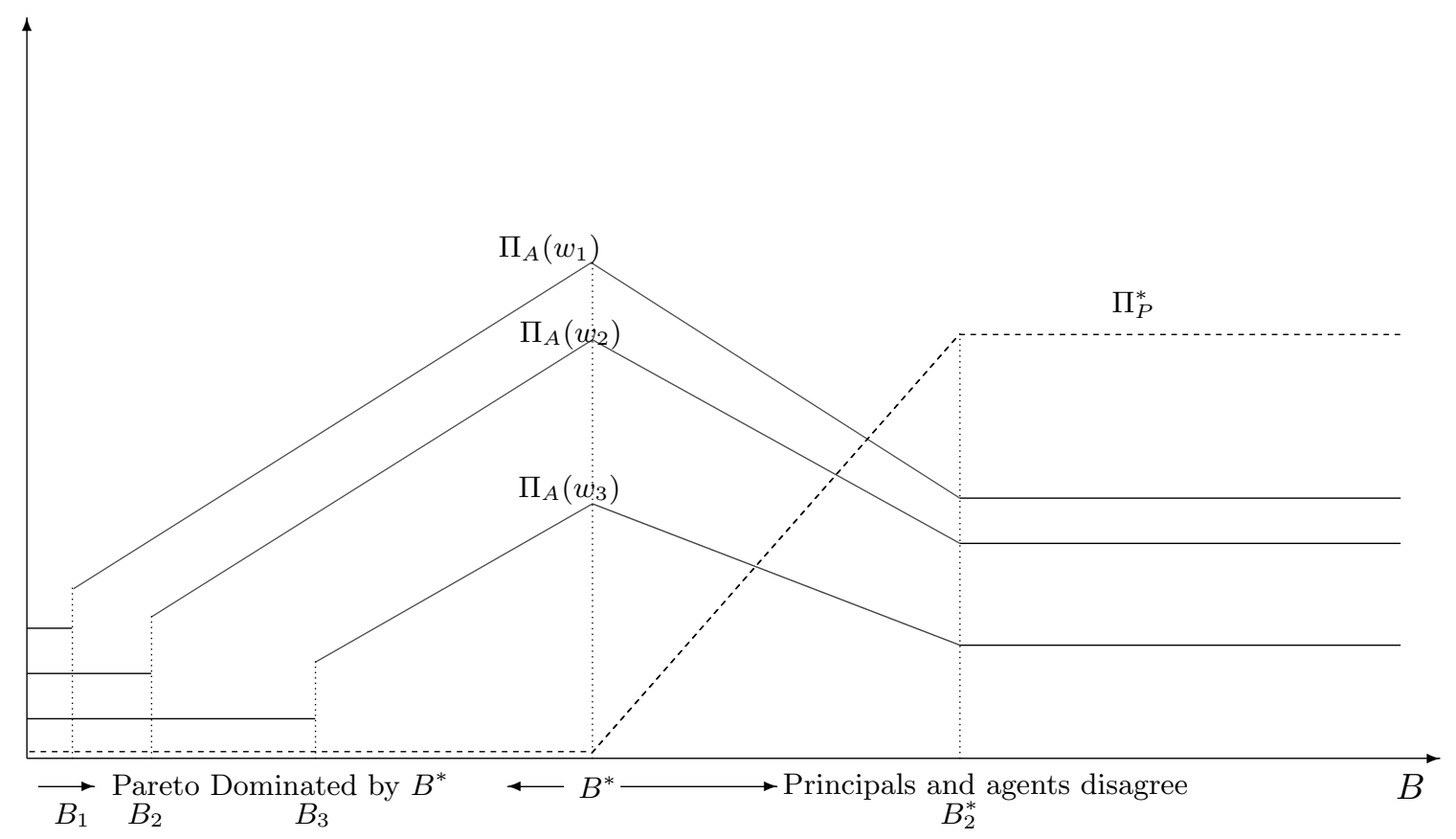

Figure 1: Payoff of Agents and Principals as Bonded Labor Limit Varies

starts operating as principals can now earn positive profits owing to full capacity utilization, and the payoffs of all active agents decline. Hence local increases in B below $B^{*}$ are (weakly) Pareto improving, while those above $B^{*}$ result in opposite effects on payoffs of principals and agents. This payoff pattern obtains irrespective of whether bonding is distortionary or non-distortionary.

In contrast, the effects on effort and efficiency of greater bonding opportunities do depend on whether it is distortionary. For an agent with wealth $w$, we can measure efficiency by the sum of the agent's equilibrium payoff and the payoff of the principal this agent is matched with, i.e., the equilibrium profit rate.

Proposition 8 (A) Suppose bonded labor is non-distortionary $B<l^{*}$ and agent with wealth $w_{m}$ is viable at $B$. Then, in any stable allocation, effort and efficiency of every matched agent are locally (weakly) increasing in $B$. 
(B) Suppose bonded labor is distortionary: $B>l^{*}$, and agent with wealth $w_{m}$ is viable at $B$.

1. The range of wealth levels over which the first best is implementable is strictly decreasing in $B$.

2. If $g$ is strictly convex at $l^{*}$ and $\hat{w}$ denotes the smallest wealth level at which the first best is implementable, there exists a right-neighborhood of $\hat{w}$ for which efficiency and effort will decline for all agents in that neighborhood following a small rise in $B$.

3. Suppose further that the bonded labor limit B is 'sufficiently' distortionary in the sense that

$$
Q(B)>e_{F} D^{\prime \prime}\left(e_{F}\right)
$$

and the marginal agent is poor in the sense that $w_{m}<\gamma(B)-S(R)$. Then there exists $\epsilon>0$ such that all agents with $w \in\left[w_{m}, w_{m}+\epsilon\right)$ receive a contract with effort $e(w)$ exceeding first-best effort $e_{F}$ and maximal bonded labor in the failure state $\left(b_{f}(w)=B\right)$. For agents in this wealth range, both effort and bonded labor are strictly increasing in B, implying that efficiency is decreasing in $B$.

In the non-distortionary case, we saw that an increase in bonding limits cause efforts to generally increase or remain unchanged. Moreover, in this case effort is always underprovided if it is not already at the first-best (in which case the rise in bonding limit has no effect). Hence efficiency always rises or remains unchanged with an increase in nondistortionary bonding. Part (B) of the above Proposition shows this is no longer true if bonding is distortionary. The adverse GE effect of a higher bonding limits causes some wealthy agents operating at the first-best to stop doing so, with a reduction in effort and use of distortionary bonded labor. Efficiency also declines amongst the poorest matched agents. If the marginal agent is viable but poor enough to earn informational rents, the case covered in Proposition 6 above, we saw that the equilibrium effort of this agent is $e^{*}(B)$. If bonding at the limit is sufficiently distortionary (as described by condition (7)), the effort of the marginal agent exceeds the first-best level. Proposition 6 also established that agents belonging to an entire interval of wealths constituting a right-neighborhood of $w_{m}$ choose a level of effort higher 
than the marginal agent. Hence there is an interval of (low) wealths which over-provide effort. An increase in bonding limits causes all these agents to raise efforts even further, as well as raise the extent of bonding, both of which cause a decline in efficiency. Figure 2 illustrates effort effects of a rise in $B$, for cases where the effort varies continuously or discontinuously with wealth.

One respect in which our characterization of the equilibrium is not complete in the case of distortionary bonding pertains to predictions concerning efforts of agents with an intermediate level of wealth, i.e., those who are credit-constrained, yet do not belong to either of the two groups considered in Propositions 6 or 7. These agents are not operating at the bonded labor limit, and at the same time are utilizing some bonded labor. In the case considered in Proposition 8, it is clear that equilibrium effort will be non-monotonic in wealth (as shown in Figure 2): for very poor agents operating at the bonded labor limit, effort is above the first-best. At the same time for a range of wealths close to those large enough to permit achievement of the first-best, effort lies below the first-best level. In between these two ranges, effort must be somewhere decreasing. These non-monotonicities reflect the underlying non-convexity of the contracting problem with distortionary bonded labor: the pattern of contracts and corresponding efforts may exhibit discontinuous changes over this intermediate region. If there exists some range of wealths in the intermediate region where effort is smoothly decreasing in wealth, an increase in bonding limits serves to redistribute wealth between the agents concerned and the principals they are matched with, which will induce their efforts to rise. This will contrast with the effect on agents at or 'close' to the first-best, for whom efforts will decline. Hence it is difficult to predict the effects on efforts, bonded labor or efficiency for agents with intermediate wealth.

\section{Political Economy Implications}

The preceding results concerning effects of changes in the bonding limit on equilibrium payoffs have interesting implications for the political economy of bonding regulations.

Corollary 2. All agents have single-peaked preferences over the bonding limit, with the peak located at $B^{*}$. All principals have single-peaked preferences over the bonding limit, 

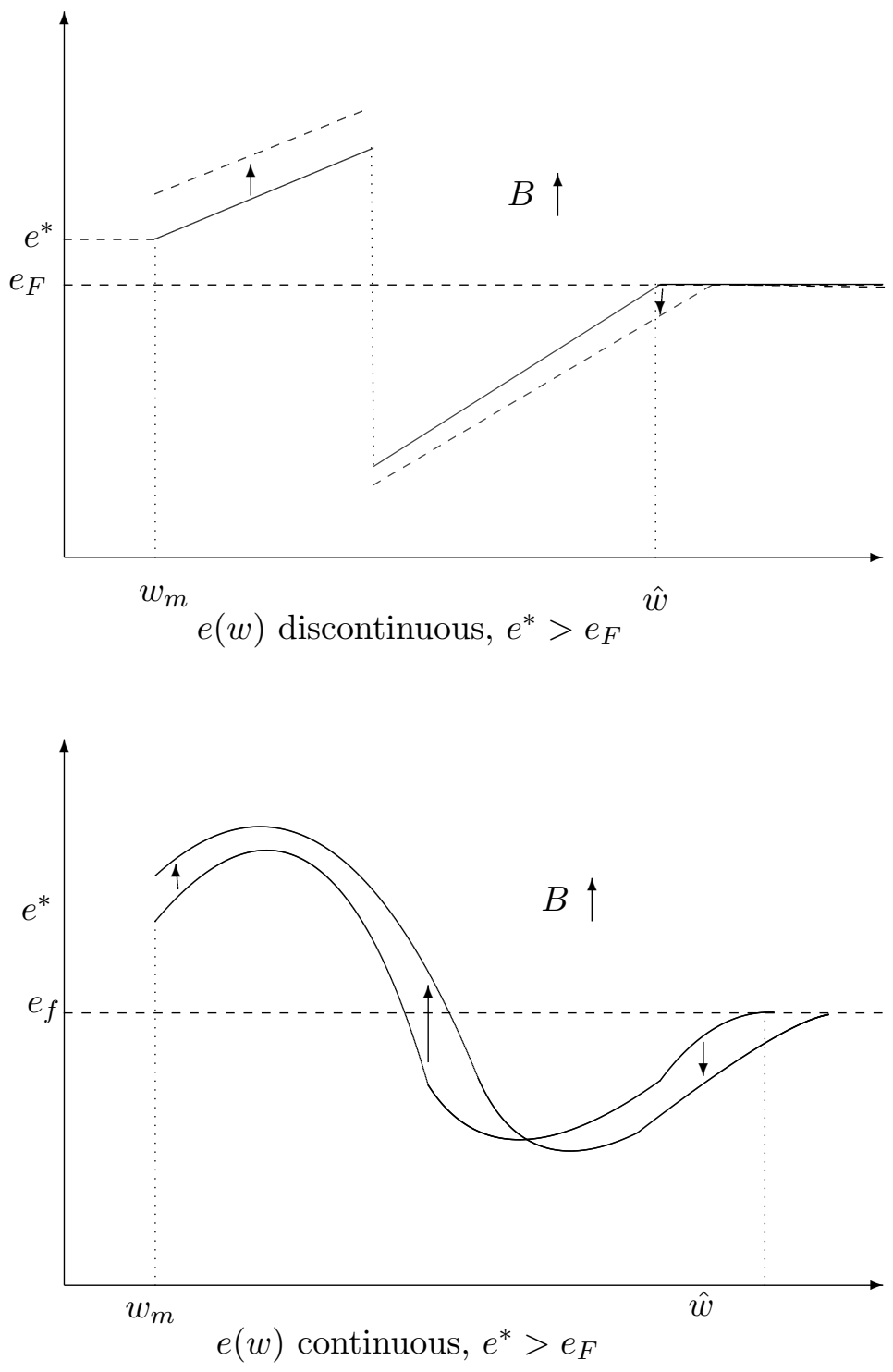

Figure 2: Effort Effects Resulting From Higher Bonding Limit $B$ 
located at $B_{2}^{*}$.

The single-peakedness of preferences is evident in Figure $1 .{ }^{13}$ If agents outnumber principals, the bonding limit that will prevail under majority rule will be $B^{*}$, under some weak assumptions about how ties are resolved. ${ }^{14}$

Now consider how the majority-winning policy $B^{*}$ varies with the wealth distribution. Suppose we compare two societies identical in all respects, except that agents are wealthier in society $\mathrm{R}$ than in society $\mathrm{P}$ in the sense of first order dominance. Then the marginal matched agent in society $R$ will be wealthier than in society $P$, i.e., society $R$ will have a lower bonding limit. ${ }^{15}$ This is illustrated in Figure 3.

This provides an explanation for the process of development to be generally associated with an evolution towards lower limits on bonding. The process of financial development is typically associated with greater availability of liquid assets that agents can use as collateral to precommit to high effort (cf. as described for the United States in the first half of the 19th century by Coleman (1974)). This represents a shift in the distribution of collateralizable wealth of borrowers, which the model predicts will give rise to laws restricting bonding (which was observed in the case of the United States in the 19th century).

A similar line of reasoning is used in Klein and Roberts (1994). They argue that the

\footnotetext{
${ }^{13}$ Of course we are excluding the uninteresting case where the marginal agent is wealthy enough to achieve the first-best at every positive bonding limit, in which case $B^{*}=0$ and a rise in $B$ has no effect on the equilibrium.

${ }^{14}$ Note that we made the extreme assumption that each principal has the capacity to fund one project. More realistically, principals will be able to fund more than one project, and there will be more agents that could be potentially active than principals, so $B^{*}$ will be the majority-rule-winning policy. Even in the case of unit capacity per principal, agents $k>m$ will never obtain a contract so will be indifferent between all bonding limits, while there will be an equal number $(m)$ of matched agents and principals with opposing preferences. Hence there will be a tie between $B^{*}$ and $B_{2}^{*}$. It is reasonable to suppose that agents with wealth below $w_{m}$ will vote for $B^{*}$ e.g., if they vote at a prior stage where they are uncertain about what their initial wealth will be, they will strictly prefer $B^{*}$ over $B_{2}^{*}$. Alternatively, they are more likely to be altruistic towards other agents rather than principals, so the same result obtains if they resolve ties to favor agents rather than principals.

${ }^{15}$ Recall from the definition of $B^{*}$ that it is the largest $B$ such that $\pi_{P}\left(w_{m}, B\right)=0$. The result follows from the fact that the P-optimal profit is rising in wealth and in the bonding limit.
} 


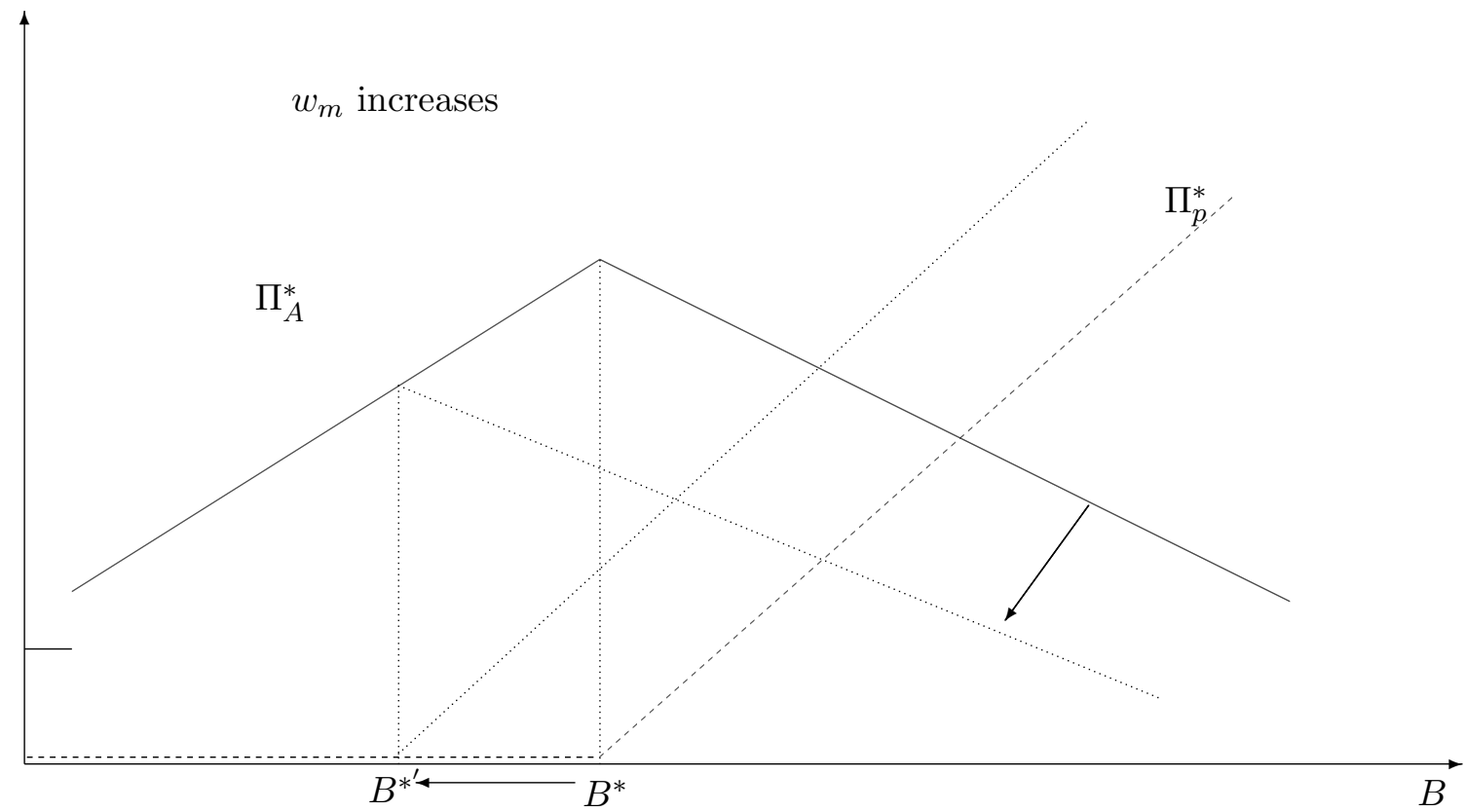

Figure 3: Payoff Effect on Intra-Marginal Agent of Raising Collateralizable Wealth of Marginal Agent

resurgence of 'pawning' of family members in French West Africa in the 1930s owed to the economic misery following the collapse of crop prices, combined with absence of alternative means of security. As they describe the institution, a 'pawn was a person transferred from one kinship group to another as security for a loan...the decision was usually taken by the household head...In the absence of clear title to land or any other mortgageable possessions, people became the only possible form of security...The creditor fed and lodged the pawn, who worked for him until such time as the debt was repaid.' (Klein and Roberts (1994, p.305)) The incidence of pawning rose sharply in the early 1930s, owing partly to poor harvests, collapsing peanut prices, and inflexible tax demands of the French colonial administration. They go on to state that 'In societies where famine was a regular occurrence, pawning was a traditional survival mechanism....The problem, however, was in the process of resolving 
itself. Incomes were already rising, and they were to rise even more after World War II....Our oral sources have suggested that in French West Africa it disappeared quickly after the war.... When disaster struck again in the years after 1968, pawning seems not to have been a serious option to those in need. By this time, fathers no longer had the same control over their families, there were relief supplies available, and for most, there were other sources of credit available.' (op.cit., p. 316).

Of course, the ceteris paribus assumption underlying our explanation can be questioned: higher levels of development are associated not just with a rightward shift of the distribution of wealth or of collateralizable assets. The supply of assets and credit can expand, i.e., $m$ can increase, which tends to lower $w_{m}$ for a given wealth distribution, and thus raise $B^{*}$. Expansion on the supply-side can moderate the effects of rightward shifts in the distribution of wealth or of alternative collateral instruments. On the other hand, the political power of borrowers relative to lenders often grows with increasing democratization, which can also lead to progressive imposition of limits on bonding. Apart from providing detailed predictions concerning the effects of changes in different parameters, our model allows for a multitude of ways that the development process can affect the evolution of restrictions on bonding.

\section{$7 \quad$ Related Literature}

Braverman and Stiglitz (1982) discuss the role of bonded labor in motivating effort incentives and risk-taking, but do not provide a welfare analysis. Srinivasan (1980, 1989) examines determinants of worker preferences for bonded labor clauses vis-a-vis credit contracts where default is followed by denial of credit in the future, and their effects on technological innovation. However, he does not provide a welfare analysis of bonded labor laws.

Our analysis is more closely related to Genicot (2002), who provides an argument for banning bonded labor used by a monopolistic landlord to preempt competition from a moneylender who cannot employ bonded labor. In her model, banning bonded labor generates greater competition between the landlord and the moneylender, and thus may increase welfare for poor farmers. This is analogous to our GE effect. However the specific nature of the 
GE effect is quite different. Genicot's analysis is based on a specific market structure (with three parties) and an exogenous allocation of bargaining power. The effect on competition among principals arises in her framework owing to the assumed asymmetry of capacity to employ bonded labor across different principals: the restriction on bonded labor "levels the playing field". In our setting all principals have the same capacity to employ bonded labor, so the effect of restricting bonded labor does not induce greater symmetry among principals. Moreover, in our framework the allocation of bargaining power between any matched principal-agent pair is endogenous. Our GE effect is thus not driven through an ad hoc asymmetry in contractual instruments and bargaining power.

Genicot and Ray (2006) consider the impact of improving contract enforcement in a credit market. In their model, the impact of improved enforcement depends crucially on the allocation of bargaining power. If agents have all the bargaining power a contract corresponding to our A-optimal contract will be employed. Consequently, agents cannot be worse off. In contrast, if principals have all the bargaining power, a P-optimal contract will be employed. Then, agents can be worse off due to improved enforcement if their participation constraint is not binding to begin with. Our analysis departs from theirs in several important dimensions. First of all, we endogenize the allocation of bargaining power in a general equilibrium framework. Furthermore, we are able to derive the political economic implications of changes in the wealth distributions and show that agents with different wealth are affected differently from a ban of bonded labor. ${ }^{16}$ Finally, we show that banning bonded labor may lead to a reduction in productive efficiency, a result not possible in the Genicot and Ray (2006) framework.

The contrast between partial equilibrium and general equilibrium effects of imposing legal restrictions on contracts is also similar to arguments in Basu (2003) and Basu and Van (1998). ${ }^{17}$ Basu (2003) investigates the welfare implications of banning sexual harassment in the workplace. In Basu and Van (1998) a ban of child labor is analyzed. While banning child labor renders every family worse off in partial equilibrium, these effects might be overturned by the general equilibrium impact on the wage rate. However, Basu and Van

\footnotetext{
${ }^{16}$ In Genicot and Ray (2006) agents have no wealth that can be used as collateral.

${ }^{17}$ See also the related discussions in Kanbur (2004).
} 
employ a Walrasian model in which there are multiple equilibria all of which are productively and Pareto-efficient. Hence the issue of productivity or efficiency implications of child labor restrictions cannot be addressed in their framework.

Our focus on the political determinants of the law is shared by a number of recent papers on law and finance. Lilienfeld-Toal and Mookherjee (2008) examine the role of general equilibrium effects in explaining standard observed features of personal bankruptcy law (interpreted as a restriction on default liability, combined with a ban on bonded labor). That paper also employs a model of matching with contracts subject to moral hazard, and incorporates (in contrast to this paper) a context of variable loan or project size. Pagano and Volpin (2005) and Biais and Mariotti (2008) use feedback effects from the labor market to firms profits to understand opposing interests of firms and workers when it comes to different regulatory regimes. Pagano and Volpin (2005) ask how investor protection and employment protection are determined in a political process. Biais and Mariotti (2008) consider the wage rate dynamics due to a change of corporate bankruptcy law.

Our paper also relates to the more broader question of inalienability of human capital and restrictions to the freedom of contracting. Bond and Newman (2006) rationalize prohibitions on punishments in private contracts by referring to a negative externality. A strong punishment in a private contract today (for example a privately stipulated stay in prison) may lead to the inability of the punished party to work tomorrow. This in turn creates a negative externality w.r.t. tomorrow's potential trading partner. This externality may then make it optimal to limit privately stipulated punishments. Anderlini, Felli and Postlewaite (2009) give a rationale why courts do not always enforce every contractual term. In their model, a reluctant court can serve as a commitment device to overcome problems due to informational asymmetries. Andolfatto (2002) sheds light on the question why the law limits the alienability of human capital. In his model, there are two classes of agents, the patient and the impatient. The impatient only care about consumption today and and will therefore enter the contract that maximizes their consumption today - even if this contract will leave them with minimum consumption tomorrow. The patient agents do not only care about their own consumption today and tomorrow but also about other agents' consumption. In the absence of regulation the impatient agents will end with the minimal consumption to- 
morrow which creates a negative externality to the patient agents. This negative externality is then the reason why there is political demand for a restriction of private contracts. Our explanation for banning bonded labor is not based on an externality but on the general equilibrium implications.

\section{Conclusion}

To summarize, this paper presents a tractable general equilibrium contracting model in which changes in bonding regulations give rise to contrasting PE and GE effects. With regard to payoffs we find that the GE effects overwhelm PE effects, and all agents are affected the same way by a rise in the bonding limit, which is opposite to the way that all principals are affected. Increases in the 'demand side' of the model - a rise in the number of agents relative to principals, or a rise in their collateralizable wealths — will cause all agents to favor a reduction in the legal limit on bonding. If bonding is distortionary, this can enhance efficiency, as well as reduce inequality between welfares of agents and principals.

In future work, we hope to extend the model of this paper to a dynamic framework, where debt can be carried forward into the future. This kind of framework may be useful to understand the impact of varying legal rules concerning lender rights in the event of default, on savings and the dynamics of the distribution of wealth. 


\section{Notes}

1. For a description of bonded labor contracts in different developing countries see U.S. Department of Labor (2005).

2. Corresponding results for the case of a single monopolist principal who owns all the land can be derived from analysis of the P-optimal contracts. In this case the general equilibrium effects will not appear, and the comparative statics with respect to liability rules will be quite different.

3. The assumption on convexity of marginal disutility of effort simplifies the analysis considerably, as it implies that the cost of providing the agent with appropriate effort incentives (i.e., inclusive of the incentive rents) is convex.

4. Note that we are assuming that the contract is not defaulted upon, or renegotiated ex post. The previous version of this paper showed that the analysis extends straightforwardly if we allow such renegotiation. Moreover, if default is possible but subject to penalties imposed by third-party enforcers, similar results apply to the effects of varying legal limits on such penalties. See the earlier version of this paper for an extended discussion of the relation between limits on contractual liability and default penalties repectively. We focus on contract liability since this is the common-sense interpretation of bonded labor: i.e., bans on bonded labor are usually taken to mean restriction on contracts, rather than rule out imprisonment as a penalty for breach of contract.

5. As the proof shows, this is the case where the agent is being offered the 'kink' contract characterized by the effort where both incentive and participation constraints are binding. This effort level at the kink contract rises as the incentive cost function drops, and the cost of ensuring the agent's participation is unchanged.

6. Ignoring the $\mathrm{PC}$ constraint, the minimum expected cost $C(e, w ; B)$ to the principal of implementing effort $e$ is obtained by selecting $b_{f}$ and $v_{f}$ to minimize $v_{f}+e D^{\prime}(e)+$ $(1-e) Q\left(b_{f}\right)$ subject to $v_{f} \geq-g\left(b_{f}\right), l^{*} \leq b_{f} \leq B$. As a result, the principal maximizes $\Pi=f+e(s-f)+g\left(b_{f}\right)-e D^{\prime}(e)-(1-e) Q\left(b_{f}\right)+w+S(R)-I$ by choice of $e, b_{f}$. 
Hence $\Pi=P(e)+S(R)+g\left(b_{f}\right)-(1-e) Q\left(b_{f}\right)+w-I=P(e)+R \cdot b_{f}+e \cdot Q\left(b_{f}\right)+w-I$ is increasing in $b_{f}$ at any $e$, so it is optimal to set $b_{f}=B$, and the principal's profit reduces to $(5)$. 


\section{References}

Aghion, Philip and Patrick Bolton (1997). "A Trickle-Down Theory of Growth and Development," Review of Economic Studies, 64, 151-72.

Basu, Kaushik (2003). "The Economics and Law of Sexual Harassment in the Workplace." Journal of Economic Perspectives, 17 (3), 141-57.

Basu, Kaushik and Pham Hoang Van (1998). "The Economics of Child Labor". American Economic Review, 88, (3), 412-27.

Berkowitz, Jeremy and Michelle White (2004). "Bankruptcy and Small Firms' Access to Credit". RAND Journal of Economics, 35(1), 69-84.

Biais, Bruno and Thomas Mariotti (2008). "Credit, Wages and Bankruptcy Laws," IDEI Toulouse Working Paper, n. 289. Forthcoming, Journal of European Economic Association.

Braverman, Avishay and Joseph E. Stiglitz (1982). "Sharecropping and the Interlinking of Agrarian Markets". The American Economic Review, 72 (4), 695-715.

Coleman, Peter J. (1974). Debtors and Creditors in America: Insolvency, Imprisonment for Debt, and Bankruptcy, 160\%-1900, State Historical Society of Wisconsin, Madison.

Dam, Kaniska and David Perez-Castrillo (2006)." The Principal-Agent Matching Market," Frontiers of Theoretical Economics, Berkeley Electronic Press, vol. 2(1), pp. 1-31.

Edmonds Eric and Salil Sharma (2005). "Investments in Children Vulnerable to Bondage," mimeo, Department of Economics, Dartmouth College. http://www.dartmouth.edu/\%7Eeedmonds/kamaiya.pdf

Genicot, Garance (2002). Bonded Labor and Serfdom: A Paradox of Voluntary Choice. Journal of Development Economics, 67 (1), 101-27.

Gropp, Reint, John Karl Scholz, and Michelle White (1997). "Personal Bankruptcy and Credit Supply and Demand". Quarterly Journal of Economics, 112(1), 217-51.

Holmstron, Bengt and Jean Tirole (1997). "Financial Intermediation, Loanable Funds and the Real Sector," Quarterly Journal of Economics, 112, 663-691.

Joshi, Sushma (2003). Bonded to Labor, Samar, Issue no. 16. 
http://www.samarmagazine.org/archive/issue.php?issue_num=16.

Kanbur, Ravi (2004). "Obnoxious Markets." in Stephen Cullenberg and Prasanta Pattanaik (editors) Globalization, Culture and the Limits of the Market: Essays in Economics and Philosophy, Oxford University Press.

Klein, Martin A. and Richard Roberts (1994). "The Resurgence of Pawning in French West Africa During the Depression of the 1930s," in Toyin Falola and Paul E. Lovejoy (editors), Pawnship in Africa : debt bondage in historical perspective, Westview Press, Boulder.

La Porta, Rafael, Florencio Lopez-De-Silanes, Andrei Shleifer, and Robert W. Vishny (1997). "Legal Determinants of External Finance", The Journal of Finance, 52(3), 1131-1150.

La Porta, Rafael, Florencio Lopez-de-Silanes, Andrei Shleifer, and Robert W. Vishny (1998). "Law and Finance", The Journal of Political Economy, 106(6), 1113-1155. Lester, V. Markham (1995). Victorian Insolvency : Bankruptcy, Imprisonment for Debt, and Company Winding-up in Nineteenth-Century England, Clarendon Press, New York; Oxford University Press, Oxford.

Lilienfeld-Toal, Ulf von and Dilip Mookherjee (2008). Why Exemption Limits? Bankruptcy Law, Inequality and Moral Hazard, mimeo, Boston University.

Mookherjee, Dilip (1997). "Informational Rents and Property Rights in Land," in John Roemer (edited) Property Rights, Incentives and Welfare, Macmillan.

Pagano, Marco, and Paolo F. Volpin (2005). "The Political Economy of Corporate Governance", American Economic Review, 95(4), 1005-1030.

Roth, Alvin E. and Marilda Sotomayor (1990). Two-Sided Matching: A Study in Game-Theoretic Modeling and Analysis, Cambridge, Cambridge University Press.

Srinivasan, T N (1980). "Bonded Labor Contracts and Incentives to Adopt Yield-raising Innovations in 'Semi-Feudal' Agriculture," Indian Economic Review, 14, 165-9.

Srinivasan, T N (1989). "On Choice Among Creditors and Bonded Labor Contracts," in P. Bardhan (edited), The Economic Theory of Agrarian Institutions, Clarendon Press, Oxford.

U.S. Department of Labor (2005). Forced and Bonded Child Labor, Bureau of Interna- 
tional Labor Affairs, http://www.dol.gov/ILAB/media/reports/iclp/sweat2/bonded.htm Westermann, William Linn (1955). The Slave Systems of Greek and Roman Antiquity. American Philosophical Society, Philadelphia.

\section{Appendix: Proofs}

Proof of Proposition 1: To prove (a), note that an increase in $w$ or $B$ enlarges the set of allocations satisfying constraints (FT), (BL), (EAIC), (EPIC), $\left(P C_{A}\right)$ and $\left(P C_{P}\right)$. For an increase in $B$ this is obvious: only constraint (BL) is affected and this is relaxed. With an increase in $w$, a corresponding increase in $v_{s}$ and $v_{f}$ preserves all the constraints apart from $\left(P C_{P}\right)$, and relaxes $\left(P C_{P}\right)$.

To prove (b), suppose instead $b_{i}<\min \left\{B, l^{*}\right\}$. Then it is feasible to raise $b_{i}$ to $l^{*}$ without creating any deadweight loss. Supplementary labor supply $l_{i}^{s}$ then falls to 0 , while $l_{i}$ is unchanged at $l^{*}$. So constraint (FT) is relaxed, and all others are preserved.

For the first part of (c), note first that every feasible allocation requires $e>0$. Otherwise if $e=0$, and the principal's payoff is $w+S(R)-I+f-v_{f}-Q\left(l_{f}\right)$, while the agent's payoff is $v_{f}$. Now $\left(P C_{A}\right)$ implies $v_{f} \geq w+S(R)$, so the principal's payoff is bounded above by $f-I-Q\left(l_{f}\right) \leq f-I<0$, and $\left(P C_{P}\right)$ must be violated.

Next, note that (FL) cannot bind in both states in any pairwise $\mathrm{PE}$ allocation. Otherwise in both states $v_{i}=R l_{i}^{s}-g\left(l_{i}\right) \leq R l_{i}-g\left(l_{i}\right) \leq S(R)$, so $\Pi_{A}=e v_{s}+(1-e) v_{f}-D(e)<S(R)$ as $e>0$, and $\left(P C_{A}\right)$ must be violated. Hence (FL) can bind in at most one state.

We claim this must be state $i=f$. Otherwise $v_{s}=R l_{s}^{s}-g\left(l_{s}\right) \leq R l_{s}-g\left(l_{s}\right) \leq S(R)$, and $e>0$ implies via (EAIC) that $v_{f}<v_{s} \leq S(R)$, so $\left(P C_{A}\right)$ must be violated.

Finally, the second part of (c) follows from the fact that if $b_{f}>l^{*}$ and $t_{f}<w-I_{A}+f$, it is possible to lower $b_{f}$ slightly, and raise $t_{f}$ so as to leave $v_{f}=w-I_{A}+f-t_{f}-g\left(b_{f}\right)$ unchanged. This contract is feasible, generates the same expected payoff for the agent, but raises the principal's expected payoff $\Pi_{P}=w+S(R)-I+e s+(1-e) f-v_{f}-e D^{\prime}(e)-(1-e) Q\left(b_{f}\right)$ since $Q$ is strictly increasing at any $b_{f}>l^{*}$. This completes the proof of Proposition 1.

The Proof of Propositions $4-7$ rely on the following set of Lemmas.

Lemma 9 Suppose $B>l^{*}$. The P-optimal contract for an agent of wealth $w$ with bonded labor limit 
$B$ involves selecting effort e to maximize $\Pi \equiv f+e(s-f)-C(e, w ; B)+w+S(R)-I$ where

$C(e, w ; B)= \begin{cases}e D^{\prime}(e)-g(B)+(1-e) Q(B), & \text { if } w<\alpha(e)-S(R)-g(B) ; \\ w+S(R)+D(e), & \text { if } w>\alpha(e)-S(R)-g\left(l^{*}\right) ; \\ w+S(R)+D(e)+(1-e) Q\left(g^{-1}(\alpha(e)-w-S(R))\right), & \text { otherwise. }\end{cases}$

and $\alpha(e) \equiv e D^{\prime}(e)-D(e)$.

Proof. Part (b) of Proposition 1 implies $l_{f} \geq \min \left\{l^{*}, B\right\}=l^{*}$, since $B>l^{*}$. Hence $l_{f}^{s}=0$, and the minimum expected $\operatorname{cost} C(e, w ; B)$ to the principal of implementing effort $e$ is obtained by selecting $l_{f}$ and $v_{f}$ to minimize $v_{f}+e D^{\prime}(e)+(1-e) Q\left(l_{f}\right)$ subject to $v_{f} \geq-g\left(l_{f}\right), l^{*} \leq l_{f} \leq$ $B, v_{f}+e D^{\prime}(e)-D(e) \geq w+S(R)$. It is obvious that in the solution $v_{f}=\max \left\{-g\left(l_{f}\right), w+S(R)-\alpha(e)\right\}$. Then the problem is to select $l_{f} \in\left[l^{*}, B\right]$ to minimize the maximum of two functions $\gamma\left(l_{f}\right) \equiv$ $(1-e)\left[S(R)-R l_{f}\right]-e g\left(l_{f}\right)$ and $\delta\left(l_{f}\right) \equiv w+S(R)-\alpha(e)+(1-e) Q\left(l_{f}\right)$. Note that $\gamma$ is decreasing and $\delta$ is increasing. Also $\delta\left(l_{f}\right)>\gamma\left(l_{f}\right)$ if and only if $w+S(R)-\alpha(e)>(1-e)\left[S(R)-R l_{f}\right]-e g\left(l_{f}\right)--g\left(l_{f}\right)$. Hence the optimal solution entails selecting $l_{f}$ according to

$$
l_{f}^{P}(e, w ; B)= \begin{cases}B, & \text { if } w<\alpha(e)-S(R)-g(B) ; \\ l^{*}, & \text { if } w>\alpha(e)-S(R)-g\left(l^{*}\right) ; \\ \left.g^{-1}(\alpha(e)-w-S(R))\right), & \text { otherwise. }\end{cases}
$$

From this we obtain expression (8) for the expected cost of implementing $e$.

Lemma 10 Suppose $B \leq l^{*}$. The P-optimal contract for an agent of wealth $w$ with bonded labor limit $B$ involves selecting effort e to maximize $\Pi \equiv f+e(s-f)-C(e, w ; B)+w+S(R)-I$ where

$$
C(e, w ; B)=\max \left\{w+S(R)+D(e), e D^{\prime}(e)+S(R)-R B\right\}
$$

Proof. $B \leq l^{*}$ implies $l_{f}=l^{*}$ and $l_{f}^{s}=l^{*}-b_{f}$. Now effort $e$ will be implemented at minimum cost to $P$ by selecting $v_{f}, b_{f}$ to minimize $v_{f}+e D^{\prime}(e)$ subject to $v_{f} \geq R\left[l^{*}-b_{f}\right]-g\left(l^{*}\right)=S(R)-$ $R b_{f}, b_{f} \in[0, B], v_{f}+\alpha(e) \geq w+S(R)$. Clearly the optimal solution involves $b_{f}=B$ and so $v_{f}=\max \{S(R)-R B, w+S(R)-\alpha(e)\}$, from which (10) follows.

Lemma 11 The A-optimal contract relative to $\Pi$ for an agent of wealth $w$ with bonded labor limit $B$ involves selecting effort e to maximize $U \equiv f+e(s-f)-D(e)-(1-e) Q\left(l_{f}(e, w, \Pi, B)\right)+[S(R)+$ $w-I-\Pi]$ subject to $e \in\left[e_{1}(w, \Pi, B), e_{2}(w, \Pi, B)\right]$, an interval corresponding to the inequality

$$
f+e(s-f)+w-I-e D^{\prime}(e)-\Pi \geq-R B-e Q(B) .
$$

where the function $l_{f}(e, w, \Pi, B)$ is defined below in (13). 
Proof. The problem is to find $v_{f}, e, b_{f}$ to maximize $v_{f}+\alpha(e)$ subject to $b_{f} \in[0, B]$ and

$$
S(R)+f+e(s-f)-e D^{\prime}(e)+w-I-\Pi-(1-e) Q\left(l_{f}\right) \geq v_{f} \geq R l_{f}^{s}-g\left(l_{f}\right)
$$

where $l_{f}^{s}=\max \left\{l^{*}-b_{f}, 0\right\}$ and $l_{f}=\max \left\{l^{*}, b_{f}\right\}$. Clearly $e$ is implementable if and only if there exists $v_{f}, b_{f} \in[0, B]$ such that

$$
S(R)+f+e(s-f)-e D^{\prime}(e)+w-I-\Pi \geq(1-e) Q\left(l_{f}\right)+R l_{f}^{s}-g\left(l_{f}\right) .
$$

Note that

$$
R l_{f}^{s}-g\left(l_{f}\right)+(1-e) Q\left(l_{f}\right)=R \max \left\{l^{*}-b_{f}, 0\right\}-g\left(l_{f}\right)+(1-e)\left[R l^{*}-g\left(l^{*}\right)-R l_{f}+g\left(l_{f}\right)\right]
$$

is decreasing in $b_{f}$, since the first term on the RHS is non-increasing in $b_{f}$, and the derivative of the RHS with respect to $l_{f}$ is $-(1-e) R-e g^{\prime}\left(l_{f}\right)<0$, and $l_{f} \equiv \max \left\{l^{*}, b_{f}\right\}$ in turn is non-decreasing in $b_{f}$. Hence a necessary and sufficient condition for $e$ to be implementable is that (FEA') is satisfied at $b_{f}=B$, i.e., that

$S(R)+f+e(s-f)-e D^{\prime}(e)+w-I-\Pi \geq(1-e) Q\left(\max \left\{l^{*}, B\right\}\right)+R \max \left\{l^{*}-B, 0\right\}-g\left(\max \left\{l^{*}, B\right\}\right)$.

In the case where $B>l^{*}$, the RHS of $(12)$ reduces to $(1-e) Q(B)-g(B)=-e g(B)+(1-e)[S(R)-$ $R B]$, so $e$ is implementable if and only if (recall $P(e)$ denotes $f+e(s-f)-e D^{\prime}(e)$ ):

$$
w-I-\Pi-P(e) \geq-e S(R)-(1-e) R B-e g(B)=-e Q(B)-R B
$$

which is condition (EFF). On the other hand, if $B \leq l^{*}$ the RHS of (12) reduces to $r\left[l^{*}-B\right]-g\left(l^{*}\right)=$ $S(R)-R B$, so in this case also we obtain the condition (EFF).

The set of implementable efforts forms an interval because the left hand side of (12) is concave in $e$, while the right hand side is linear in $e$. Let this interval be denoted $\left[e_{1}(w, \Pi, B), e_{2}(w, \Pi, B)\right]$.

Note that $e$ is not implementable if and only if

$$
w-I-\Pi+P(e)<-R B-e Q(B)
$$

or

$$
w<w_{1}(\Pi, e, B) \equiv I+\Pi-P(e)-R B-e Q(B) .
$$

In the case where $B \leq l^{*}$, we have $Q\left(l_{f}\right)=Q\left(l^{*}\right)=0$. Hence $v_{f}=S(R)+P(e)+w-I-\Pi$ and the A-optimal contract reduces to maximizing $v_{f}+\alpha(e)=f+e(s-f)-D(e)+w-I+S(R)-\Pi$ subject to $e \in\left[e_{1}(w, \Pi, B), e_{2}(w, \Pi, B)\right]$. 
Now consider the case $B>l^{*}$. Given an implementable $e$, the smallest $l_{f} \in\left[l^{*}, B\right]$ will be selected to implement it, since the LHS of (FEA) is decreasing in $l_{f}$ and it is optimal to set $v_{f}$ equal to the LHS of (FEA). This is given by

$$
l_{f}(e, w, \Pi, B)= \begin{cases}l^{*}, & \text { if } w \geq w_{2}(\Pi, e) ; \\ l(e, w, \Pi), & \text { if } w \in\left(w_{1}(\Pi, e, B), w_{2}(\Pi, e)\right) ;\end{cases}
$$

where $l(e, w, \Pi)$ solves for $l$ in the equation

$$
w-I-\Pi+P(e)=-R l-e Q(l)
$$

and $w_{2}(\Pi, e) \equiv I+\Pi-P(e)-R l^{*}$.

Moreover, $v_{f}$ will be set equal to $S(R)+f+e(s-f)+w-I-e D^{\prime}(e)-(1-e) Q\left(l_{f}(e, w, \Pi, B)\right)-\Pi$. Therefore the objective function reduces to expression $U$.

Lemma 12 Suppose $B>l^{*}$. The A-optimal contract relative to $\Pi$ for an agent with wealth $w$ has the following properties.

(a) If e is implementable (i.e., $w>w_{1}(\Pi, e, B)$ ), its implementation necessitates distortionary bonded labor $\left(l_{f}(e, w, B)>l^{*}\right)$ if and only if $w<w_{2}(\Pi, e)$.

(b) If $w>w_{2}\left(\Pi, e_{F}\right)$ then the A-optimal contract relative to $\Pi$ achieves the first-best utility $U_{F} \equiv$ $f+e_{F}(s-f)-D\left(e_{F}\right)+w-I-\Pi+S(R)$, i.e., sets $e=e_{F}$ and $l=l^{*}$.

(c) If $w<w_{2}\left(\Pi, e_{F}\right)$ then the first-best is not implementable.

Proof. (a) is obvious. For (b) note that if $w>w_{2}\left(\Pi, e_{F}\right)$ then $l\left(e_{f}, w, \Pi\right)=l^{*}$, and it is feasible to achieve first-best utility with $e=e_{F}$ and $l=l^{*}$. For (c) then $l>l^{*}$ is needed to implement $e_{F}$, so the first-best utility is not achievable.

Lemma 13 Suppose $B \leq l^{*}$. Then the P-optimal profit of a principal contracting with an agent with wealth $w$ equals

$$
\pi_{P}(w, B)=w-I-\max _{e}\left\{e D^{\prime}(e)+S(R)-R B, w+S(R)+D(e)\right\}
$$

and optimal effort is given as follows:

(a) If $w<\alpha(\tilde{e})-R B$ then $e=\tilde{e}$.

(b) If $w \in\left(\alpha(\tilde{e})-R B, \alpha\left(e_{F}\right)-R B\right)$ then $e=e(w)$, the solution for e in $\alpha(e)-R B=w$. 
(c) If $w>\alpha\left(e_{F}\right)-R B$ then $e=e_{F}$.

The agent's expected utility in case (a) equals $\alpha(\tilde{e})-R B+S(R)$ which strictly exceeds $w+S(R)$. In cases (b) and (c) the expected utility equals $w+S(R)$.

Proof. In the case where $B \leq l^{*}$, we have $Q(l)=0$ for every $l \leq B$. Therefore expression (8) for the expected cost to the principal of implementing $e$ reduces to $\max \left\{e D^{\prime}(e)+S(R)-R B, w+\right.$ $D(e)+S(R)\}$. This is a convex function, the upper envelope of the functions $e D^{\prime}(e)+S(R)-R B$ and $w+D(e)+S(R)$ corresponding to the $(\mathrm{BL})$ and $\left(P C_{A}\right)$ constraints respectively. Now $\tilde{e}$ is the maximizer of $e(s-f)-e D^{\prime}(e)$, while $e_{F}$ is the maximizer of $e(s-f)-D(e)$. It follows that $\tilde{e}$ is the P-optimal effort if $\tilde{e} D^{\prime}(\tilde{e})-R B>w+D(\tilde{e})+S(R)$, whence only the (BL) constraint binds. This corresponds to case (a). On the other hand $e_{F}$ is the P-optimal effort if $e_{F} D^{\prime}\left(e_{F}\right)-R B<$ $w+S(R)+D\left(e_{F}\right)$, whence only the $\left(P C_{A}\right)$ constraint binds (case (c)). In case (b), the optimal effort lies at the kink point where the two functions are equal, and both constraints bind.

Lemma 14 Suppose $B \leq l^{*}$. Then the A-optimal problem (for a viable agent with wealth $w$ ) relative to profit $\Pi$ reduces to selecting e to maximize $f+e(s-f)-D(e)+w-I-\Pi$ subject to the constraint

$$
P(e)+w+R B-I-\Pi \geq 0
$$

and the optimal effort is described as follows:

$$
e_{A}(w ; \Pi, B)=\min \left\{e_{F}, \hat{e}(w, \Pi \mid B)\right\}
$$

where $\hat{e}(w, \Pi \mid B)$ denotes the largest solution for e in the equation $P(e)=\Pi+I-w-R B$.

Proof. The first part follows from applying Lemma 11 to the case where $B \leq l^{*}$. For the second part, note that if an agent is viable, there will exist at least one level of $e$ at which (AOP) is satisfied. Since $\tilde{e}$ is the level of $e$ where $P(e)$ is maximized, it will be satisfied at $\tilde{e}$. Since $P$ is concave, the set of implementable efforts will be an interval. If $e_{F}$ is implementable then the unconstrained optimum which is achieved at $e_{F}$, is implementable. This happens when $P\left(e_{F}\right)+w+R B-I-\Pi \geq 0$. If this condition does not hold we have $P\left(e_{F}\right)+w+R B-I-\Pi<0$. Recall that $e_{F}$ is the maximizer of $e(s-f)-D(e)$, so $P($.$) is strictly decreasing at e_{F}$. Hence the set of implementable efforts is bounded above by $e_{F}$, implying that the A-optimal effort is the highest $e$ which is implementable, i.e., must equal $\hat{e}(w, \Pi \mid B)$. 
Proof of Propositions 4 and 5: Proposition 4 follows from the derivation of the P-optimal contract as derived in Lemma 13. Proposition 5 follows from the derivation of the A-optimal contract in Lemma 14. Note that $e(w)$ is constant in $B$ since $\Pi_{B}^{*}=R$ and hence the RHS of $f+e(s-f)-$ $\left.e D^{\prime}(e)=\Pi^{*}+I-w-R B\right)$ is unaffected by a change in $B$.

\section{Proof of Proposition 6}

Part (i): Consider the P-optimal contract for the agent with wealth $w_{m}$.

Ignoring the $\mathrm{PC}$ constraint, the minimum expected cost $C(e, w ; B)$ to the principal of implementing effort $e$ is obtained by selecting $b_{f}$ and $v_{f}$ to minimize $v_{f}+e D^{\prime}(e)+(1-e) Q\left(b_{f}\right)$ subject to $v_{f} \geq-g\left(b_{f}\right), l^{*} \leq b_{f} \leq B$. As a result, the principal maximizes $\Pi=f+e(s-f)+g\left(b_{f}\right)-e D^{\prime}(e)-$ $(1-e) Q\left(b_{f}\right)+w+S(R)-I$ by choice of $e, b_{f}$. Since $\Pi=P(e)+S(R)+g\left(b_{f}\right)-(1-e) Q\left(b_{f}\right)+w-I=$ $P(e)+R \cdot b_{f}+e \cdot Q\left(b_{f}\right)+w-I$ is increasing in $b_{f}$ at any $e$ it is optimal to set $b_{f}=B$. Hence, the $\mathrm{P}$-optimal problem which ignores the $\mathrm{PC}$ constraint for an agent with $w_{m}$ is equivalent to:

$$
\max _{e} P(e)-(1-e) Q(B)+g(B) .
$$

This is solved at $e^{*}$. The $\mathrm{PC}$ constraint is satisfied at $e^{*}$ because $\alpha\left(e^{*}\right)-g(B) \geq w_{m}+S(R)$ by assumption. Hence, this is the $\mathrm{P}$-optimal contract and

$$
\Pi^{*}=P\left(e^{*}\right)+e^{*} \cdot Q(B)+w_{m}+R \cdot B-I .
$$

Optimal effort $e^{*}$ is increasing in $B$ since $e^{*}$ solves $P^{\prime}(e)+Q(B)=0, Q(B)$ increases in $B$ and $P^{\prime}(e)$ is decreasing in $e$ at $e^{*}$. The profit effect is $\Pi_{B}^{*}=e^{*} \cdot Q^{\prime}(B)+R>0$ due to the Envelope Theorem.

Using $\gamma(B)$ to denote the marginal agent's payoff,

$$
\begin{aligned}
\gamma(B)= & f+e^{*}(s-f)-D\left(e^{*}\right)-\left(1-e^{*}\right) Q(B)+S(R)+w-I-\Pi^{*}(B) \\
= & f+e^{*}(s-f)-D\left(e^{*}\right)-\left(1-e^{*}\right) \cdot Q(B)+S(R)+w_{m}-I \\
& -P\left(e^{*}\right)-e^{*} Q(B)-w_{m}-R B+I \quad \text { (using equation (6)) } \\
= & \alpha\left(e^{*}\right)-Q(B)+S(R)-R \cdot B=\alpha\left(e^{*}\right)-g(B)
\end{aligned}
$$

The marginal agent's payoff decreases in B since (upon using $e_{B}^{*}(B)$ to denote $\partial e^{*}(B) / \partial B$ ):

$$
\gamma^{\prime}(B)=\alpha^{\prime}\left(e^{*}(B)\right) \cdot e_{B}^{*}(B)-g^{\prime}(B)=e^{*}(B) \cdot D^{\prime \prime}\left(e^{*}\right) \cdot e_{B}^{*}(B)-g^{\prime}(B) .
$$

From

$$
\begin{array}{r}
P^{\prime}\left(e^{*}\right)+Q(B)=0 \\
\Leftrightarrow s-f+Q(B)=e^{*} \cdot D^{\prime \prime}\left(e^{*}\right)+D^{\prime}\left(e^{*}\right)
\end{array}
$$


we get $Q^{\prime}(B)=\left[e^{*} D^{\prime \prime \prime}\left(e^{*}\right)+2 \cdot D^{\prime \prime}\left(e^{*}\right)\right] \cdot e_{B}^{*} \geq 2 D^{\prime \prime}\left(e^{*}\right) \cdot e_{B}^{*}$.

From this it follows that $D^{\prime \prime}\left(e^{*}\right) \cdot e_{B}^{*} \leq \frac{Q^{\prime}(B)}{2}<Q^{\prime}(B)$ and hence

$$
\gamma^{\prime}(B)<e^{*} \cdot Q^{\prime}(B)-g^{\prime}(B)<Q^{\prime}(B)-g^{\prime}(B)=-R<0 .
$$

(ii): Suppose to the contrary that every $w$ in a right neighborhood of $w_{m}$ chooses $b_{f}(w)<B$. Then, Lemma 11 implies that for every such $w$ it is true that $e(w)<e_{2}\left(w, \Pi^{*}, B\right)$, i.e.:

$$
s-f-D^{\prime}(e(w))+Q\left(l_{f}\left(e(w), w, \Pi^{*}, B\right)\right)-(1-e(w)) \cdot Q^{\prime}\left(l_{f}\left(e(w), w, \Pi^{*}, B\right)\right) \cdot \frac{\partial l_{f}}{\partial e} \leq 0 .
$$

The A-optimal problem relative to $\Pi^{*}$ satisfies the conditions for the Maximum Theorem, hence the optimal solution is u.s.c. in $w$. Taking limits as $w \rightarrow w_{m}$, we must have $e(w) \rightarrow e^{*}$ and $l_{f} \rightarrow B$ implying

$$
s-f-D^{\prime}\left(e^{*}\right)+Q(B) \leq 0
$$

since $\frac{\partial l_{f}\left(e^{*}, w, \Pi^{*}, B\right)}{\partial e}=-\frac{P^{\prime}\left(e^{*}\right)+Q(B)}{e^{*} \cdot Q^{\prime}(B)+R}=0$. This contradicts $(15)$ since $s-f+Q(B)-D^{\prime}\left(e^{*}\right)=$ $e^{*} D^{\prime \prime}\left(e^{*}\right)>0$.

We now show that the A-optimal payoff of any agent $\Pi_{A}(w)$ with wealth $w$ who is bonding at the limit $\left(b_{f}(w)=B\right)$ equals $\alpha(e(w))-g(B)$. For any such agent, the induced effort is the largest solution to

$$
P(e)+e Q(B)-I+w+R B=\Pi^{*}(B) .
$$

Hence

$$
\Pi_{A}=f+e(w) \cdot(s-f)-D(e(w))-(1-e(w)) \cdot Q(B)+S(R)+w-I-\Pi^{*}(B)
$$

Using equation (17),

$$
\begin{array}{r}
\Pi_{A}=f+e(w) \cdot(s-f)-D(e(w))-(1-e(w)) \cdot Q(B)+S(R)+w \\
-P(e(w))-e(w) \cdot Q(B)-w+I-R \cdot B \\
=\alpha(e(w))-g(B) .
\end{array}
$$

We claim that this payoff is decreasing in $B$. Differentiating with respect to $B$, we obtain

$$
\frac{\partial \Pi_{A}}{\partial B}=\alpha^{\prime}(e(w)) \cdot e_{B}(w)-g^{\prime}(B)=e \cdot D^{\prime \prime}(e) \cdot e_{B}-g^{\prime}(B)
$$

where $e=e(w)$ and $e_{B}=\frac{\partial \hat{e}\left(w, \Pi^{*} \mid B\right)}{\partial B}$. Using (17) and differentiating w.r.t. $B$, we obtain

$$
\left[P^{\prime}(e)+Q\right] \cdot e_{B}+e \cdot Q^{\prime}(B)+R=\Pi_{B}^{*}
$$


where $Q=Q(B)$ and $Q^{\prime}=Q^{\prime}(B)$. Using (6) we get

$$
\Pi_{B}^{*}=e^{*} Q^{\prime}(B)+R
$$

and hence (20) implies

$$
e_{B}=\frac{\left(e-e^{*}\right) Q^{\prime}}{-\left(P^{\prime}+Q\right)}
$$

Thus

$$
\frac{\partial \Pi_{A}}{\partial B}=\frac{e D^{\prime \prime}(e)\left(e-e^{*}\right)}{-\left(P^{\prime}+Q\right)} Q^{\prime}-g^{\prime}
$$

Now define the function $F(e) \equiv \frac{-\left[P^{\prime}(e)+Q(B)\right]}{e D^{\prime \prime}(e)}$ and note that $F\left(e^{*}(B)\right)=0$ and $F(e)>0$ for any $e>e^{*}(B)$. Moreover we have at any $e>e^{*}(B)$

$$
F^{\prime}(e)=\frac{e D^{\prime \prime}\left[e D^{\prime \prime \prime}+2 D^{\prime \prime}\right]-\left[e D^{\prime \prime}+D^{\prime}-(s-f+Q)\right]\left[e D^{\prime \prime \prime}+D^{\prime \prime}\right]}{\left(e D^{\prime \prime}\right)^{2}}>1
$$

since by hypothesis $b_{f}=B$, implying

$$
\begin{aligned}
s-f+Q & -D^{\prime} \geq\left.(1-e) \cdot Q^{\prime} \cdot \frac{\partial l_{f}}{\partial e}\right|_{l_{f}=B} \\
& =(1-e) \cdot Q^{\prime} \cdot \frac{-\left[P^{\prime}+Q\right]}{R+e Q^{\prime}}>0 .
\end{aligned}
$$

From (23), we obtain

$$
\frac{\partial \Pi_{A}}{\partial B}=\frac{\left(e-e^{*}\right)}{F(e)} Q^{\prime}(B)-g^{\prime}(B) .
$$

Now $\frac{e-e^{*}}{F(e)}=\frac{e-e^{*}}{F(e)-F\left(e^{*}\right)}<1$ since $F\left(e^{*}\right)=0$ and $F^{\prime}(e)>1$ for every $e>e^{*}$. Hence

$$
\frac{\partial \Pi_{A}}{\partial B}<Q^{\prime}(B)-g^{\prime}(B)=-R<0
$$

i.e., the payoff of agents bonding at the limit $B$ is strictly decreasing in $B$.

(iii): For agents using $b_{f}(w)=B$, the argument follows from (ii) above. For other agents, the constraint (EFF) does not bind and only the GE effect operates, so $\frac{\partial \Pi_{A}}{\partial B}=-\Pi_{B}^{*}<0$.

(iv): follows from Lemma 12. This completes the proof of Proposition 6.

Proof of Proposition 7: Define $B_{2}^{*}$ as the largest $B$ for which $l_{f}\left(w_{m}\right)=B$ (and $B_{1}^{*} \leq B_{2}^{*}$ by construction).

(i): In this case the contract described in part (a) for $w_{m}$ violates the PC constraint for $w_{m}$. Hence, the PC constraint is binding in the P-optimal contract with $w_{m}$ and the $w_{m}$ agent is offered the 'kink' contract where

$$
\begin{array}{r}
e_{m} \cdot D^{\prime}\left(e_{m}\right)+(1-e) \cdot Q(B)-g(B)=w+S(R)+D\left(e_{m}\right)+\left(1-e_{m}\right) \cdot Q(B) \\
\Leftrightarrow \alpha\left(e_{m}\right)-g(B)=w+S(R)
\end{array}
$$


Hence,

$$
\begin{array}{r}
\Pi^{*}=f+e_{m}(s-f)-e_{m} D^{\prime}\left(e_{m}\right)-\left(1-e_{m}\right) Q(B)+g(B)+w_{m}+S(R)-I \\
=P\left(e_{m}\right)+e_{m} Q(B)+R B+w_{m}-I
\end{array}
$$

and it must be the case that $e_{m}>e^{*}$ or $-\left(P^{\prime}\left(e_{m}\right)+Q\right)>-\left(P^{\prime}\left(e^{*}\right)+Q\right)=0$. From equation $(29)$ we have

$$
\begin{array}{r}
e_{m} D^{\prime \prime}\left(e_{m}\right) e_{m B}=g^{\prime} \\
\Leftrightarrow e_{m B}=\frac{g^{\prime}}{e_{m} D^{\prime \prime}\left(e_{m}\right)}>0
\end{array}
$$

Differentiating equation (30) we get

$$
\Pi_{B}^{*}=\left[P^{\prime}\left(e_{m}\right)+Q\right] \cdot e_{m B}+e_{m} Q^{\prime}+R
$$

Furthermore, $\Pi_{B}^{*}>0$ follows from the fact that the 'kink' contract is offered. Existence of $\delta>0$ again follows similar to the argument used in part a) ii) above. Moreover, $e_{B}>0$ since $g^{\prime}>0, \alpha^{\prime}>0$ and $e(w)$ is determined in equation (29).

The utility of any such agent bonding at the limit is

$$
\Pi_{A}=\alpha(e(w))-g(B)
$$

for a similar reason as provided for part ((ii)) of Proposition 6. All agents with $w=w_{m}$ obtain their reservation utility which is locally independent of $B$.

It remains to show that $\frac{\partial \Pi_{A}}{\partial B}<0$ for $w \in\left(w_{m}, w_{m}+\delta\right)$. Since $P(e)+e Q(B)+w-I+R B=\Pi^{*}$ and hence

$$
\begin{aligned}
& -\left[P^{\prime}(e)+Q\right] e_{B}-e Q^{\prime}-R=-\Pi_{B}^{*} \\
& =-\left[P^{\prime}\left(e_{m}\right)+Q\right] e_{m B}-\left(e_{m} Q^{\prime}+R\right) \text { due to equation (32) } \\
& =-\frac{\left[P^{\prime}\left(e_{m}\right)+Q\right] \cdot g^{\prime}}{e_{m} D^{\prime \prime}\left(e_{m}\right)}-e_{m} Q^{\prime}-R \text { due to equation (31) }
\end{aligned}
$$

Hence,

$$
e_{B}=\frac{\left(e-e_{m}\right) \cdot Q^{\prime}-\left[P^{\prime}\left(e_{m}\right)+Q\right] \cdot \frac{g^{\prime}}{e_{m} D^{\prime \prime}\left(e_{m}\right)}}{-\left[P^{\prime}(e)+Q\right]}
$$

Since $b_{f}(w)=B$ for all $w$ in this interval, and $w>w_{m}$, we have $e>e_{m}$ and $P^{\prime}+Q<0$. Hence $e_{B}>0$ for this interval of wealth levels. As a result

$$
\begin{aligned}
\frac{\partial \Pi_{A}}{\partial B} & =e \cdot D^{\prime \prime}(e) \cdot e_{B}-g^{\prime} \\
& =\frac{e \cdot D^{\prime \prime}(e)}{-\left[P^{\prime}(e)+Q\right]}\left\{\left(e-e_{m}\right) Q^{\prime}-\left[\frac{P^{\prime}\left(e_{m}\right)+Q}{e_{m} D^{\prime \prime}\left(e_{m}\right)}-\frac{P^{\prime}(e)+Q}{e D^{\prime \prime}}\right] \cdot g^{\prime}\right\} \\
& =\frac{1}{F(e)}\left[\left(e-e_{m}\right) Q^{\prime}-\left\{F(e)-F\left(e_{m}\right)\right\} g^{\prime}\right]
\end{aligned}
$$


Since $Q^{\prime}<g^{\prime}$ and $F(e)-F\left(e_{m}\right)>e-e_{m}$ for any $e>e_{m} \geq e^{*}(B)$, equation (35) implies $\frac{\partial \Pi_{A}}{\partial B}<0$. Hence agents of wealth $w \in\left[w_{m}, w_{m}+\delta\right)$ are strictly worse off.

(ii): Agents using $b_{f}(w)=B$ are worse off since $\frac{\partial \Pi_{A}}{\partial B}<0$ as shown in part (ii) of Proposition 6 . For other agents there is no PE effect, only an adverse GE effect: $\frac{\partial \Pi_{A}}{\partial B}=-\Pi_{B}^{*}<0$.

(iii): This follows from Lemma 12 .

For $B>B_{2}^{*}$, the (EFF) constraint does not bind for $w_{m}$ and hence $\Pi_{B}^{*}=0$. We now show that it is not possible that $b_{f}(w)=B$ over any interval $\left(w^{\prime}, w^{\prime \prime}\right)$ with $w^{\prime \prime}>w^{\prime}>w_{m}$. Over such an interval, $e_{B}=\frac{e Q^{\prime}}{-\left(P^{\prime}(e)+Q\right)}$. Hence,

$$
\frac{\partial \Pi_{A}}{\partial B}=\frac{e D^{\prime \prime} \cdot e Q^{\prime}}{-\left(P^{\prime}(e)+Q\right)}-g^{\prime}=\frac{e}{F(e)} Q^{\prime}-g^{\prime}=\frac{e Q^{\prime}-F(e) g^{\prime}}{F(e)}
$$

Over any such interval, $e$ is rising in $w$. Since $b_{f}(w)=B$ and $e>e^{*}(B)$, we have $F^{\prime}(e)>1$. So the numerator of (37) is non-increasing in $w$, while the denominator is strictly increasing. Moreover, in this case, $\frac{\partial \Pi_{A}}{\partial B}$ must be nonnegative, since there is only a PE effect which is always favorable. Since $e$ will be strictly increasing in $w$ over $\left(w^{\prime}, w^{\prime \prime}\right)$, it follows that $\frac{\partial \Pi_{A}}{\partial B}$ is strictly decreasing in $w$ over this interval.

Now, by hypothesis, $b_{f}(w)=B$ for all $w \in\left(w^{\prime}, w^{\prime \prime}\right)$, and $b_{f}<B$ for all $w$ in a left neighborhood of $w^{\prime}$ and all $w$ in a right neighborhood of $w^{\prime \prime}$. Then $\frac{\partial \Pi_{A}}{\partial B}\left(w^{\prime}\right)=\frac{\partial \Pi_{A}}{\partial B}\left(w^{\prime \prime}\right)=0$ for all $w$ in a left neighborhood of $w^{\prime}$ and all $w$ in a right neighborhood of $w^{\prime \prime}$. The argument above shows that $\frac{\partial \Pi_{A}}{\partial B}(w)$ is positive and strictly decreasing in $w$ over $\left(w^{\prime}, w^{\prime \prime}\right)$. This implies that the A-optimal payoff must exhibit a discontinuity at either $w^{\prime}$ or $w^{\prime \prime}$, contradicting the property that the A-optimal contracting problem varies continuously with $B$. This completes the proof of Propsition 7 .

\section{Proof of Proposition 8:}

Part (A): This follows from the characterization results in Propositions 4 and 5.

Part (B):

1. From Lemma 12 we know that the first best is implementable if and only if $w \geq w_{2}\left(\Pi^{*}, e_{F}\right)=$ $I+\Pi^{*}-P\left(e_{F}\right)-R \cdot l^{*}$ and $\frac{\partial w_{2}}{\partial B}=-\Pi_{B}^{*}$.

2. Part 1. above ensures that the threshold for first-best implementation is locally increasing in $B$. It therefore suffices to show that A-optimal effort for agents with wealth in a left neighborhood of the threshold $\hat{w} \equiv w_{2}\left(\Pi^{*}, e_{F}\right)$ for first-best implementation is less than the first-best effort $e_{F}$ to show the decrease in effort.

Recall from Lemma 11 that the A-optimal effort $e(w)$ for an agent with wealth $w$ satisfies the 
first-order condition

$$
s-f-D^{\prime}(e(w))+Q\left(l_{f}(e(w), w)\right)-(1-e) Q^{\prime}\left(l_{f}(e(w), w)\right) \frac{\partial l_{f}(e(w), w)}{\partial e} \geq 0
$$

with equality if $e(w)$ is in the interior of the implementable interval. As $w$ converges to $\hat{w}$ from the left, we know that $e(w)$ is converging to $e_{F}$, and $l_{f}$ is converging to $l^{*}$ from the right. Hence $Q\left(l_{f}(e(w), w)\right)$ and $Q^{\prime}\left(l_{f}(e(w), w)\right)$ are converging to 0 , while $\frac{\partial l_{f}(e(w), w)}{\partial e}$ is converging to $\frac{-P^{\prime}\left(e_{F}\right)}{R}$ which is positive and bounded. Hence $\left[Q\left(l_{f}(e(w), w)\right)-(1-e) Q^{\prime}\left(l_{f}(e(w), w)\right) \frac{\partial l_{f}(e(w), w)}{\partial e}\right]$ is converging to 0 . Moreover it must be converging to 0 from the left, as

$$
\lim _{l_{f} \rightarrow l^{*}+} \frac{Q^{\prime}\left(l_{f}\right)}{Q\left(l_{f}\right)}=\lim _{l_{f} \rightarrow l^{*}+} \frac{Q^{\prime \prime}\left(l_{f}\right)}{Q^{\prime}\left(l_{f}\right)}=\lim _{l_{f} \rightarrow l^{*}+} \frac{g^{\prime \prime}\left(l_{f}\right)}{-R+g^{\prime}\left(l_{f}\right)}=\infty .
$$

Hence (38) ensures that $s-f-D^{\prime}(e(w))$ is converging to 0 from the right.

At $B$ the first-best threshold is $\hat{w}$. If $B$ goes up slightly to $B^{\prime}$, the threshold $\hat{w}$ goes up, say to $\tilde{w}$. Then over the interval $(\hat{w}, \tilde{w})$ effort is less than the first-best as shown above. Now, owing to Lemma 12 , the agent selects $b_{f}(w)>l^{*}$ over this interval. Previously they were at $l^{*}$. So efficiency falls over this interval.

3. We know that $w_{m}$ receives a contract involving $e^{*}(B)$ which solves $s-f-D^{\prime}(e)-e D^{\prime \prime}(e)+$ $Q(B)=0$. Hence, if $-e_{F} D^{\prime \prime}\left(e_{F}\right)+Q(B)>0$ it follows that $e^{*}(B)>e_{F}$. The rest of the statement follows directly applying the results presented in Proposition 6 . This completes the proof of Proposition 8. 